\title{
Mitogen-Activated Protein Kinase Phosphatase 1 (MKP1) Negatively Regulates the Production of Reactive Oxygen Species During Arabidopsis Immune Responses
}

\author{
Viviana Escudero, ${ }^{1,2}$ Miguel Ángel Torres,, ${ }^{1,2}$ Magdalena Delgado,, ${ }^{1,2}$ Sara Sopeña-Torres,, ${ }^{1,2}$ \\ Sanjay Swami, ${ }^{1,2}$ Jorge Morales, ${ }^{1,2}$ Antonio Muñoz-Barrios, ${ }^{1,2}$ Hugo Mélida, ${ }^{1}$ Alan M. Jones, ${ }^{3}$ \\ Lucía Jordá, ${ }^{1,2,+}$ and Antonio Molina ${ }^{1,2,+}$ \\ ${ }^{1}$ Centro de Biotecnología y Genómica de Plantas (CBGP), Universidad Politécnica de Madrid (UPM)—Instituto Nacional de \\ Investigación y Tecnología Agraria y Alimentaria (INIA), Campus de Montegancedo, 28223-Pozuelo de Alarcón (Madrid), Spain; \\ ${ }^{2}$ Departamento de Biotecnología-Biología Vegetal, Escuela Técnica Superior de Ingeniería Agronómica, Alimentaria y de \\ Biosistemas, 28040-Madrid, Spain; and ${ }^{3}$ Departments of Biology and Pharmacology, University of North Carolina, Chapel Hill, \\ NC 27599, U.S.A.
}

Accepted 23 October 2018.

Genetic ablation of the $\beta$ subunit of the heterotrimeric $G$ protein complex in $a g b 1-2$ confers defective activation of microbe-associated molecular pattern (MAMP)-triggered immunity, resulting in agb1-2 enhanced susceptibility to pathogens like the fungus Plectosphaerella cucumerina BMM. A mutant screen for suppressors of agb1-2 susceptibility ( $s g b$ ) to $P$. cucumerina BMM identified sgb10, a new null allele ( $m k p 1-2)$ of the mitogen-activated protein kinase phosphatase 1 (MKP1). The enhanced susceptibility of agb1-2 to the bacterium Pseudomonas syringae pv. tomato DC3000 and the oomycete Hyaloperonospora arabidopsidis is also abrogated by $m k p 1-2$. MKP1 negatively balances production of reactive oxygen species (ROS) triggered by MAMPs, since ROS levels are enhanced in $\mathrm{mkp} 1$. The expression of $\mathrm{RBOHD}$, encoding a NADPH oxidase-producing ROS, is upregulated in mkp1 upon MAMP treatment or pathogen infection. Moreover, MKP1 negatively regulates RBOHD activity, because ROS levels upon MAMP treatment are increased in $m k p 1$ plants constitutively overexpressing $R B O H D(35 S:: R B O H D$ mkp1). A significant reprograming of $m k p 1$ metabolic profile occurs with more than 170 metabolites, including antimicrobial compounds, showing differential accumulation in comparison with wild-type plants. These results suggest that MKP1 functions downstream of the heterotrimeric $G$ protein during MAMP-triggered immunity, directly regulating the activity

Viviana Escudero and Miguel Ángel Torres contributed equally to this work.

${ }^{\dagger}$ Corresponding authors: L. Jordá: E-mail: lucia.jorda@upm.es and A. Molina: E-mail: antonio.molina@upm.es

Funding: This work was supported by the Secretaría de Estado de Investigación, Desarrollo e Innovación grants BIO2015-64077-R and BIO20123291, H2020 Marie Skłodowska-Curie Actions grant (SignWALLINg624721) from the European Union, the BRAVE Erasmus Mundi Program (European Union), and a PIF fellowship from Universidad Politécnica de Madrid. Work in the Jones lab was supported by grants from the NIGMS (R01GM065989) and National Science Foundation (MCB-0718202).

*The $\boldsymbol{e}$-Xtra logo stands for "electronic extra" and indicates that seven supplementary figures and five supplementary tables are published online.

() 2019 The American Phytopathological Society of RBOHD and ROS production as well as other immune responses.

The heterotrimeric $\mathrm{G}$ protein complex couples extracellular signals to intracellular responses throughout eukaryotes (Temple and Jones 2007). The heterotrimeric G protein complex comprises $\mathrm{G} \alpha, \mathrm{G} \beta$, and $\mathrm{G} \gamma$ subunits at the plasma membrane. In animals, upon catalytic activation by a cell surface $G$ protein-coupled receptor, the $\mathrm{G} \alpha$ subunit exchanges GDP for GTP, initiating the release of the G $\beta \gamma$ from the trimer. Thus, the activated G $\alpha$ and G $\beta \gamma$ interact with independent downstream effectors to transduce the signal. Heterotrimeric $G$ proteins are central for signal transduction cascades in animals, in which many genes code for the different subunits $(\mathrm{G} \alpha, \mathrm{G} \beta$, and $\mathrm{G} \gamma$ ) and the diverse gene combinations specify different responses. The Arabidopsis genome contains only one gene coding for the canonical $\mathrm{G} \alpha$ $(G P A 1)$, one for the $\mathrm{G} \beta(A G B 1)$, and three for the $\mathrm{G} \gamma(A G G 1$, $A G G 2$, and $A G G 3)$. However, Arabidopsis also has three noncanonical extra-large $\mathrm{G}$ proteins (XLGs), XLG1,XLG2, and $X L G 3$, and a seven-transmembrane regulator of $\mathrm{G}$ signaling protein (AtRGS1) as part of the complex (Chakravorty et al. 2015; Maruta et al. 2015; Urano and Jones 2014; Urano et al. 2016a; Zhu et al. 2009).

In plants, heterotrimeric $\mathrm{G}$ proteins impact development, as they regulate stomata, shoot and root development (Urano et al. 2016a). The agbl loss-of-function mutants have altered morphology, e.g., rounder leaves and short siliques among other quantitative changes (Ullah et al. 2003). These reduced organ phenotypes, observed also in hypocotyls of etiolated agbl-2 seedlings, seem to be due to the alteration of cell proliferation that is an indirect effect of the regulatory function of heterotrimeric $G$ in plant immunity (Ullah et al. 2001, 2003). In contrast, enlarged meristems in agbl-2 mutant are responsible for the changes in branching patterns (Ishida et al. 2014). Moreover, seedlings lacking $A G B 1$ are severely hypersensitive to D-glucose (Ullah et al. 2001).

Mutants with a nonfunctional AGB1 subunit or impaired in the $\gamma$ subunits (aggl agg2) are highly susceptible to a wide range of pathogens with different infection styles. These include necrotrophic fungi such as Plectosphaerella cucumerina BMM, Botritis cinerea and Alternaria brassicicola, vascular 
fungi like Fusarium oxysporum (Llorente et al. 2005; Trusov et al. 2006), biotrophic fungi such as Golovinomyces cichoracearum (Lorek et al. 2013), the biotrophic oomycete Hyaloperonospora arabidopsidis (Liu and Whitham 2013; Torres et al. 2013), bacteria such as Agrobacterium tumefaciens, Pseudomonas syringae pv. tomato DC3000, and Pseudomonas aeruginosa (Cheng et al. 2015; Ishikawa 2009; Torres et al. 2013), and viruses (Brenya et al. 2016). These data highlight the prominent role of heterotrimeric $G$ protein in plant immunity.

Plant immunity relies on cell autonomous mechanisms that activate different layers of defenses. A first layer of defense is based on plasma membrane resident immune receptors that sense pathogenic microbes, by perceiving either evolutionary conserved motifs present in the pathogens, named microbeassociated molecular patterns (MAMPs), or host-derived signals released or synthesized upon pathogen attack and that are termed damage-associated molecular patterns. Immune receptors, known as pattern recognition receptors (PRRs), are either receptor like kinases (RLKs) with an extracellular ligand-binding domain and an intracellular serine/threonine kinase-signaling domain or receptor like proteins that lack the intracellular kinase domain (Böhm et al. 2014; Couto and Zipfel 2016). These PRRs upon recognition of MAMPs activate MAMP-triggered immunity (MTI) by forming a protein complex with other recruited coreceptor proteins and receptor-like cytoplasmic kinases (RLCKs) that transduces downstream signaling inside the cell. Heterotrimeric $G$ protein serves as a converging point of different signaling activated by diverse PRRs (Aranda-Sicilia et al. 2015; Liu et al. 2013; Tunc-Ozdemir and Jones 2017). Activation of the $G$ protein occurs after the phosphorylation of the negative regulator RGS1 by some RLKs upon ligand recognition (Tunc-Ozdemir and Jones 2017; Tunc-Ozdemir et al. 2016). Moreover, XLG2 interacts directly with some PRRs, like FLS2, the receptor of bacterial MAMP flagellin (flg22), and the RLCK BIK1, stabilizing the receptor complex before elicitation. After perception of the bacterial flg22 by FLS2, phosphorylated XLG2 dissociates to activate ROS production by the NADPH oxidase RBOHD (Liang et al. 2016). In addition to heterotrimeric $\mathrm{G}$ proteins, mitogen-activated protein kinase (MAPK) signaling cascades also play a central role in the transduction of a plethora of extracellular signals ( $\mathrm{Bi}$ and Zhou 2017; Sopeña-Torres et al. 2018; Sun et al. 2018; Xu and Zhang 2015). For example, the dynamic scaffold protein receptor for activated C kinase 1 links AGB1 and the MEKK1MKK5-MPK3/6 cascade during plant immune responses (Cheng et al. 2015).

Few downstream effectors involved in Arabidopsis immune responses regulated by $\mathrm{G}$ protein are known. We identified activation tagging $s g b(s g b 1-8)$ mutants that rescued the defective hypocotyl phenotype of agbl-2 plants but did not restore defense responses (Escudero et al. 2017; Friedman et al. 2011; Wang et al. 2006). Therefore, in order to identify additional molecular components required in the immune pathways activated by AGB1, we performed an independent screening of suppressors of $a g b 1-2$ susceptibility $(s g b)$ to the fungus $P$. cucumerina BMM, using an ethyl methanesulphonate (EMS) mutagenized population of agbl-2 seeds (Escudero et al. 2017). We found that one suppressing mutant ( $s g b 11)$ that restores $a g b 1-2$ susceptibility to wild-type levels corresponds to an ESKIMO1 allele (Escudero et al. 2017). ESKIMO1 encodes a polysaccharide $O$-acetyltransferase involved in xylan acetylation (Urbanowicz et al. 2014). Here, we identified another agb1-2 suppressor, sgb10, corresponding to a new null allele of the MAPK phosphatase 1 (MKP1) (Bartels et al. 2009). We show that $m k p l$ mutants have enhanced MTI responses, including ROS production, leading to faster and more robust disease resistance responses.

\section{RESULTS}

\section{SGB10 encodes MKP1.}

To identify new molecular components of heterotrimeric G protein-mediated defense signaling, a mutant screen for suppressors of agbl-2 susceptibility to the necrotrophic fungus $P$. cucumerina BMM was performed (Escudero et al. 2017). An EMS-mutagenized M2 population of $a g b 1-2$ was inoculated with a spore suspension of $P$. cucumerina BMM $\left(4 \times 10^{6}\right.$ spores $\left./ \mathrm{ml}\right)$ and four $s g b$ mutants, $s g b 10$ to $s g b 13$, were identified that fully rescued agbl-2 enhanced susceptibility to $P$. cucumerina BMM but did not fully revert the phenotypes of agbl-2 plants associated to development (Escudero et al. 2017). These data supported that the disease resistance and developmental signaling components regulated by the heterotrimeric $\mathrm{G}$ protein are not identical, which is in line with previous data (Urano et al. 2016b). The sgblo mutant suppressed agbl-2 susceptibility to $P$. cucumerina $\mathrm{BMM}$, as fungal biomass quantification using quantitative polymerase chain reaction (qPCR) showed that $s g b 10$ agbl-2 plants displayed a fungal growth level comparable to that of the resistant irx 1-6 plants included as controls in the analyses (Fig. 1A). Remarkably, $P$. cucumerina BMM fungal biomass in sgb10 agbl-2 was quite similar to that in $s g b 10$, suggesting that $S G B 10$ is epistatic over $A G B 1$ and probably functions downstream of the heterotrimeric $\mathrm{G}$ protein in the regulation of AGB1-mediated disease resistance responses.

To map the recessive sgb10 mutation, sgb10 plants (in Col0 background) were crossed with La- 0 plants and the segregating F2 population obtained was used to fine-map sgb10 into a $0.5 \mathrm{Mb}$ region on chromosome III, between markers cer451778 (At3g55010) and cer479349 (At3g56408) (Fig. 1B). To identify the genetic lesion in $s g b 10$, full sequencing of the $s g b 10$ and Col0 genomic DNAs was performed. These genomic sequences were compared between the indicated genetic markers and two mutations were found: i) a single $\mathrm{G}$ to A transition in At3g55270 that led to a change of $\mathrm{W}^{252}$ to a stop codon in $M K P 1$ (Ulm et al. 2001), and ii) a $\mathrm{G}$ to A substitution in At3g55740 that resulted in a change of $\mathrm{W}^{114}$ to a stop codon in the proline transporter AtProT2 (Lehmann et al. 2011). To determine which of these mutations caused the sgb10 phenotype, 3-week-old null mutants in these genes, mkpl-1 (Anderson et al. 2011) and atprot2-3 (SALK_067508) (Lehmann et al. 2011), as well as sgb10, agbl2 , and wild-type plants were spray-inoculated with a spore suspension of $P$. cucumerina BMM $\left(4 \times 10^{6}\right.$ spores $\left./ \mathrm{ml}\right)$ and the progression of the infection was evaluated by fungal biomass quantification using qPCR. sgblo and mkpl-1 mutants showed reduced fungal growth in comparison with wild-type plants, while fungal biomass was similar in atprot $2-3$ and Col-0 wildtype plants (Supplementary Fig. S1).

Next, an allelism test was performed by crossing $s g b 10$ with the mkpl-1 allele and the F1 plants (three weeks old) were found to show similar developmental phenotypes as both parental lines, i.e., reduced plant size, leaf morphology alterations, and spontaneous lesions, as described previously for mkpl-1 plants (Bartels et al. 2009) (Fig. 1C; Supplementary Fig. S2). Moreover, disease resistance to P. cucumerina BMM of Col-0, agbl-2, sgblo, $\mathrm{mkpl-1}$, and F1 $\left(\mathrm{sgblO}^{+/-} \mathrm{mkpl}^{-1^{+/-}}\right)$ plants revealed that $F 1$ plants show an enhanced resistance phenotype comparable to individual sgblo and $m k p l-1$ mutants (Fig. 1D). In line with these data, we found that transgenic lines overexpressing $M K P 1$ in the $m k p l-1$ background (35S::MKPl $m k p 1-1)$ (Ulm et al. 2001) abolished the enhanced resistance to P. cucumerina BMM of mkpl-1 plants. Together, these results indicated that $s g b l 0$ is a new allele of $m k p l$ and, accordingly, 
was designated $m k p l-2$. The point mutation in $s g b 10 / m k p l-2$ introduces an early stop codon leading to the formation of a truncated protein of 251 amino acids that lacks the C-terminal part after the Tyr-phosphatase dual domain (Fig. 1B). MKP1 is a member of the five MKP-type DSP phosphatases (dualspecificity protein Tyr-phosphatase) present in the genome of Arabidopsis (Bartels et al. 2010). MKP1 plays a key role in response to UV-B stress (González Besteiro and Ulm 2013) but also negatively regulates MAPK (MPK6) phosphorylation upon MAMP treatment, bacterial disease resistance, and activation of the salicylic acid (SA) and jasmonic acid (JA) signaling pathways upon infection (Anderson et al. 2011, 2014; Bartels et al. 2009; Jiang et al. 2017a and b).

mkp1-2 suppresses agb1-2 susceptibility to the bacterium Pseudomonas syringae pv. tomato DC3000 and the oomycete $H$. arabidopsis Noco2.

Because agb1-2 displays an increased susceptibility to the bacteria Pseudomonas syringae pv. tomato DC3000 and the oomycete $H$. arabidosidis isolate Noco2 (Liu and Whitham

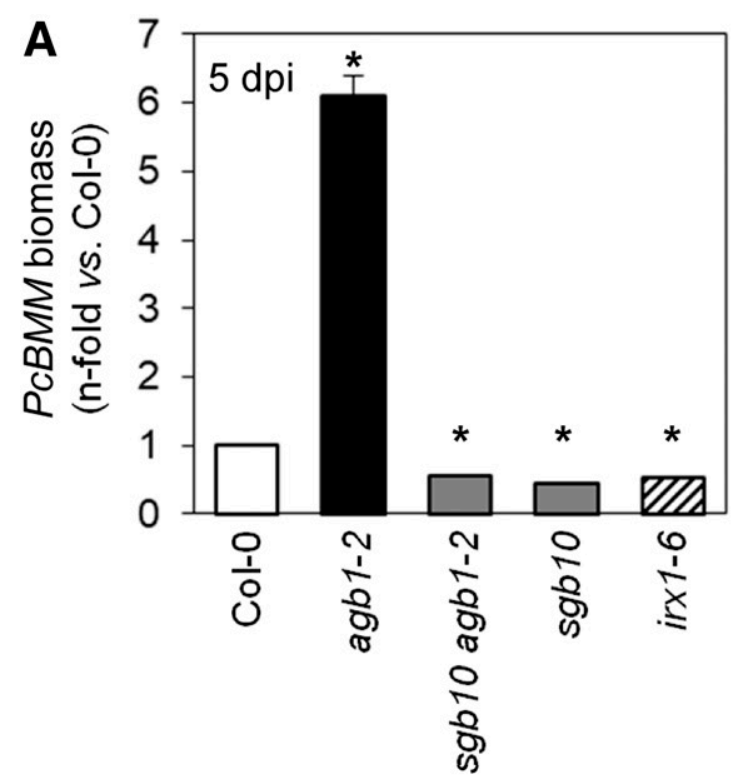

B

C
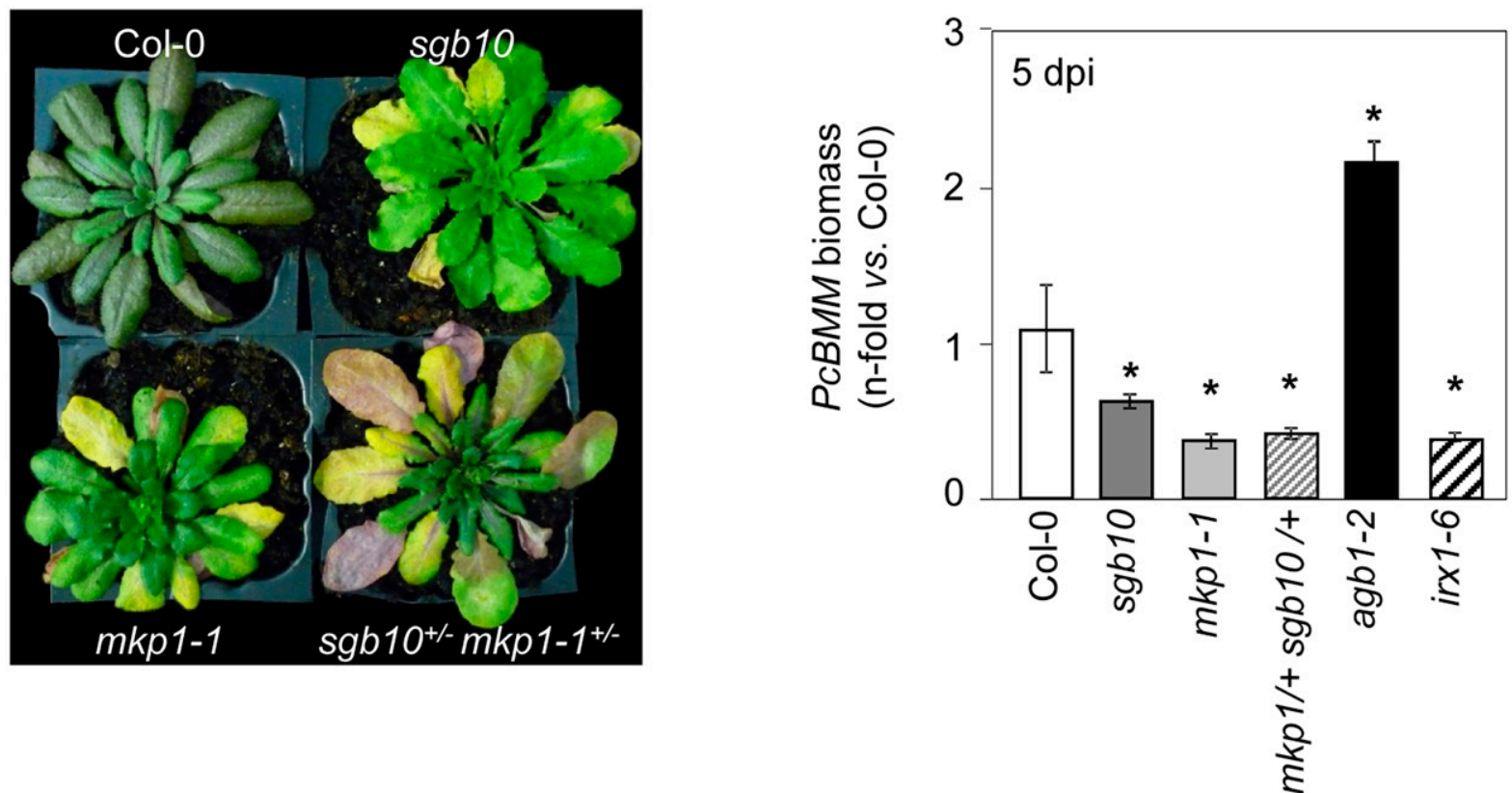

Fig. 1. sgb10 is a new mutant allele of MKP1. A, Quantification of Plectosphaerella cucumerina BMM biomass by quantitative polymerase chain reaction in plants of the indicated genotypes 5 days after spray-inoculation with a suspension of $4 \times 10^{6}$ spores/ml of the fungus. irx $1-6$ mutant plants were included as the resistance control. Values are represented as average ( \pm standard error) of the fold increase compared with Col-0 plants. Asterisks indicate the statistical significance levels according to Student's $t$ test $(P<0.05)$. B, Mapping of the SGB10 locus onto chromosome 3, into bacterial artificial chromosome T26I12, between the indicated markers. The number of recombinants is indicated in red. Gene structure of $S G B 10 / M K P 1$ showing the mutations identified in the $s g b 10$

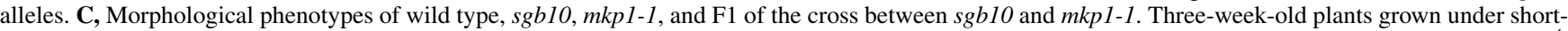
day conditions were photographed. D, Allelism test with quantification of $P$. cucumerina BMM biomass at 5 days postinoculation on the hemizygote $s g b 10^{+/}$ $m k p 1-1^{+/-}$. Asterisks indicate statistically significant differences according to Student's $t$ test $(P<0.05)$. Experiments $(\mathrm{A}$ and $\mathrm{D})$ were repeated three times with similar results. 
2013; Torres et al. 2013), we analyzed the susceptibility of mkp1-2 agbl-2 double mutant to these pathogens, to determine whether $m k p 1-2$ also restored the deficient resistance responses of $a g b 1-2$ to these pathogens. Bacterial growth was evaluated on 3-week-old Col-0, agbl-2, mkpl-2 agbl-2, and mkpl-2 plants; $f l s 2$ and $c p r 5$ plants were included as susceptible and resistant controls, respectively (Bowling et al. 1997; Zipfel et al. 2004). As shown in Figure 2A, bacterial growth in $m k p 1-2$ agbl-2 plants at 2 and 4 days postinoculation (dpi) was comparable to that observed in Col-0 plants, whereas $m k p 1-2$ plants

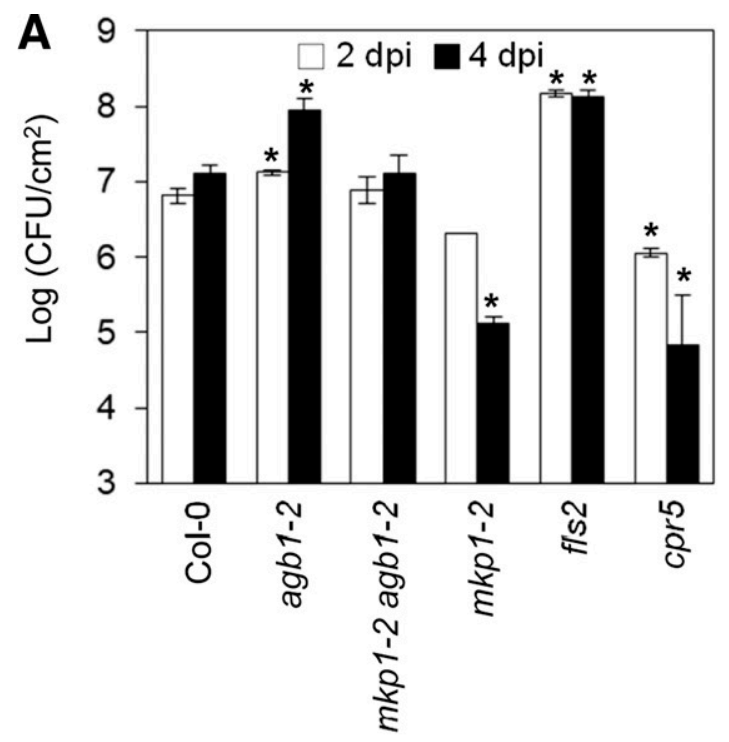

B

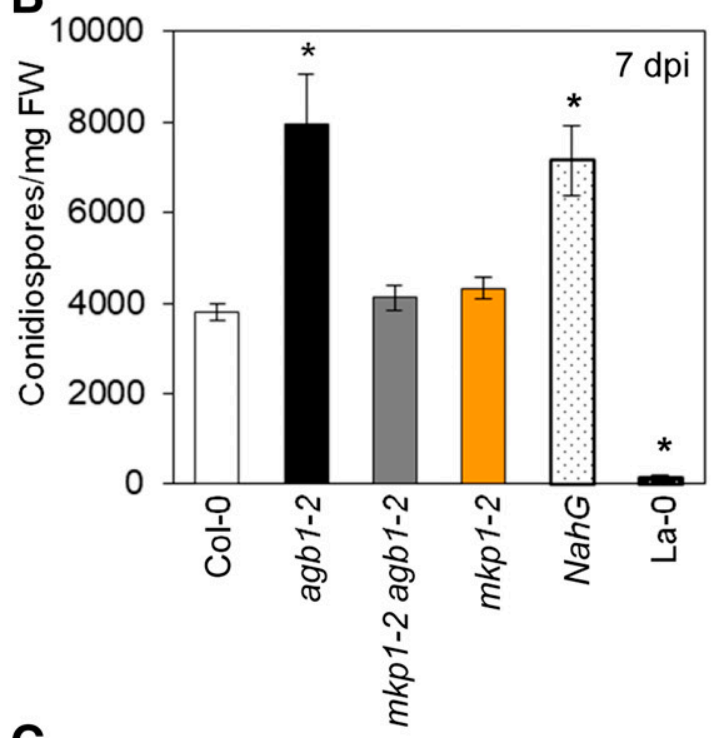

C

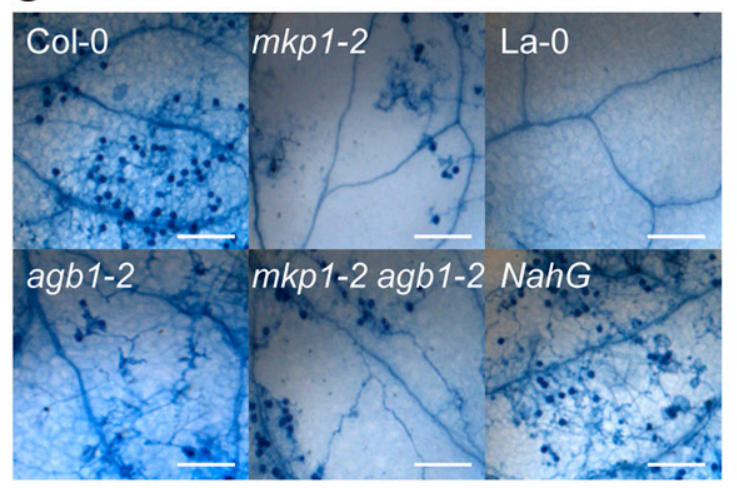

supported lower bacteria growth than wild-type plants and its enhanced resistance was comparable to that exhibited by the resistance control cpr5 plants. These data were in line with previous studies that demonstrated the involvement of MKP1 in the regulation of Arabidopsis resistance to this bacterium (Anderson et al. 2011, 2014; Bartels et al. 2009; Jiang et al. 2017a).

We also analyzed the resistance of $m k p l-2$ agbl-2 and $m k p l-$ 2 mutants to the biotrophic oomycete $H$. arabidosidis isolate Noco2. Twelve-day-old seedlings from Col-0, agb1-2, agb1-2 $m k p 1-2$, and $m k p l-2$ as well as susceptible NahG transgenic and resistant La-0 plants (harboring the PPR5 resistance gene) (Delaney et al. 1994; Parker et al. 1997) were inoculated with a suspension of $H$. arabidosidis conidiospores $\left(4 \times 10^{4}\right.$ spores/ml) (Fig. 2B). The number of $H$. arabidosidis conidiospores per milligram of fresh weight at 7 dpi was similar between $m k p 1-2$ agbl-2 and wild-type plants, indicating that $m k p 1-2$ can suppress agbl-2 hypersusceptibility to $H$. arabidosidis (Fig. 2B), whereas $m k p 1-2$ seedlings had a defense response comparable to that of Col-0 plants (Fig. 2B). Trypan blue staining at $7 \mathrm{dpi}$ corroborated these disease resistance data and showed that $H$. arabidosidis hyphae growth in mkpl-2 agb1-2, mkpl-2, and Col-0 leaves was qualitatively lower than that observed in the agbl-2 and the NahG susceptible plants (Fig. 2C). The leaves of $m k p 1-2$ agbl-2 and $m k p 1-2$ seedling did not show spontaneous necrotic lesions (Fig. 2C) in comparison with that observed in leaves of 3-week-old or older plants (Fig. 1D). Taken together, these data demonstrate that MKP1 is a negative regulator of plant disease resistance against pathogens with different lifestyles and that mutations in $M K P 1$ restore the tested agbl-2 immune deficiencies determining its enhanced susceptibility to different pathogens.

Impairment of MKP1 does not restore to wild-type levels the developmental phenotypes associated with agb1-2.

Next, we determined whether $m k p 1-2$ mutation restored the wild-type phenotypes of most of the agbl-2 associated developmental alterations observed in leaf morphology, plant height, or silique and pedicel length (Ullah et al. 2001, 2003; Urano et al. 2016a). These developmental phenotypes were compared in Col-0, agbl-2, mkpl-2 agbl-2, and mkpl-2 plants grown under short-day conditions $(10 \mathrm{~h}$ of illumination and $14 \mathrm{~h}$ of dark). We found that, in $m k p 1-2$ agbl-2, the analyzed phenotypes were not restored to wild-type levels (Supplementary Fig. S3), similarly to what has been reported for the $a g b 1-2$ sgb11/esk1-7 double mutant (Escudero et al. 2017). On the contrary, $m k p 1-2$ plants showed additional alterations in some developmental parameters, because $m k p l$ height and size was lower than that of agbl-2 mutants (Urano et al. 2016a). Moreover, the characteristic erecta-like phenotype of the rosette of $a g b 1-2$ plants was maintained in the $m k p 1-2$ agbl-2

Fig. 2. $m k p 1-2$ suppresses agb1-2 susceptibility to a wide range of pathogens. A, Quantification of Pseudomonas syringae pv. tomato DC3000 growth on the indicated genotypes at 2 and 4 days postinoculation (dpi) with bacterial suspension at an optical density at $600 \mathrm{~nm}$ of 0.2 . Results are average \pm standard error $(n=6)$. Highly susceptible $f l s 2$ and resistant $c p r 5$ mutants were included as controls. Two-tailed Student's $t$ tests for pairwise comparisons of infected plants with Col-0 plants were conducted. Asterisks indicate significant differences at $P<0.05$. B, Twelve-day-old seedlings of the indicated genotypes were inoculated with a conidia suspension of Hyaloperonospora arabidosidis isolate $\operatorname{Noco} 2\left(2 \times 10^{4}\right.$ spores $\left./ \mathrm{ml}\right)$. After 7 dpi, conidia were quantified per milligram of leaf fresh weight (FW). NahG and La-0 plants were included as susceptible and resistant controls, respectively. C, Trypan blue staining of leaves from the indicated genotypes at 7 dpi with $H$. arabidosidis Noco2. Bars $=100 \mu \mathrm{m}$. Data presented correspond to one experiment of three performed that gave similar results. 
double mutant. Also, $m k p l$ plants showed necrotic lesions associated to $\mathrm{H}_{2} \mathrm{O}_{2}$ accumulation at latter stages of development when grown under short-cycle conditions (Fig. 1C), as described previously (Anderson et al. 2011, 2014; Bartels et al. 2009).

We also tested additional $a g b l$-associated phenotypes, such as reduced hypocotyl length and early apical hook opening in dark-germinated seedlings (Wang et al. 2006), and seedling hypersusceptibility to isoxaben, an inhibitor of primary cellwall biosyntheis (Scheible et al. 2001). The hypocotyl length of mkp1-2 agbl-2 double mutant seedlings germinated in the dark was similar to that of wild-type plants, while apical hook opening of $m k p l-2 a g b l-2$ was enhanced and similar to that of the $m k p l$ single mutant (Supplementary Fig. S4). Also, the hypersensitivity to isoxaben of agbl-2 seedlings was restored to wild-type levels in the mkpl-2 agbl-2 double mutant seedlings, which were still sensitive to isoxaben in contrast to the isoxaben resistance 1 (ixrl-2) mutant included as positive control (Scheible et al. 2001). These data suggest that the $m k p l$ null mutation impacts some but not all developmental phenotypes modulated by AGB1.

\section{mkp1-2 restores the defective MAMP-triggered immune responses of $a g b 1-2$ plants.}

Heterotrimeric $G$ proteins are convergent points of PRR signaling and MAMP-triggered responses and, accordingly, the agbl-2 mutant is impaired in the activation of early immune responses (Aranda-Sicilia et al. 2015; Liang et al. 2016; Liu et al. 2013). Therefore, we evaluated whether the mkpl-2 mutation restores the deficient immune responses of $a g b 1-2$ plants after treatment with the bacterial MAMP flg22. As shown in Figure $3 \mathrm{~A}$, the defective ROS production in $a g b 1-2$ plants was
A

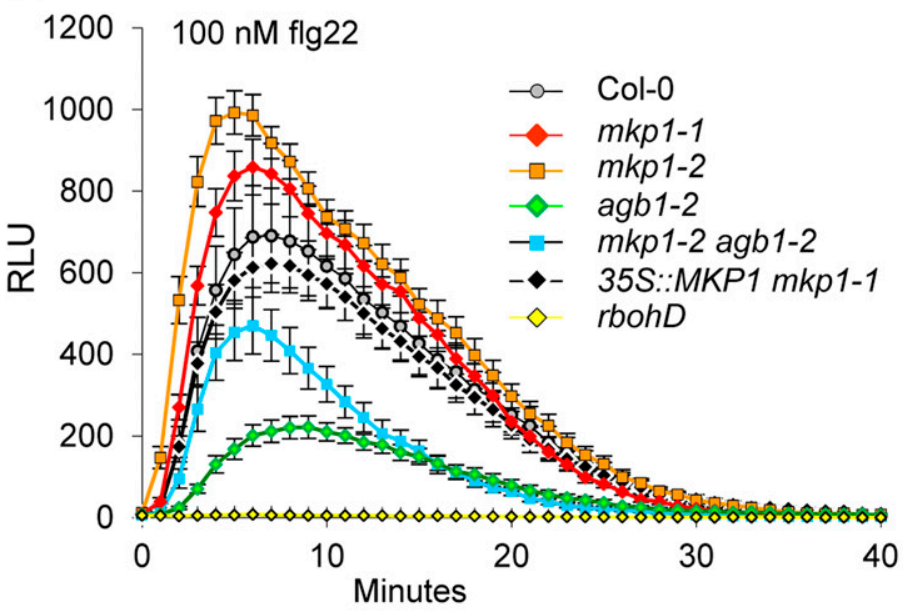

B

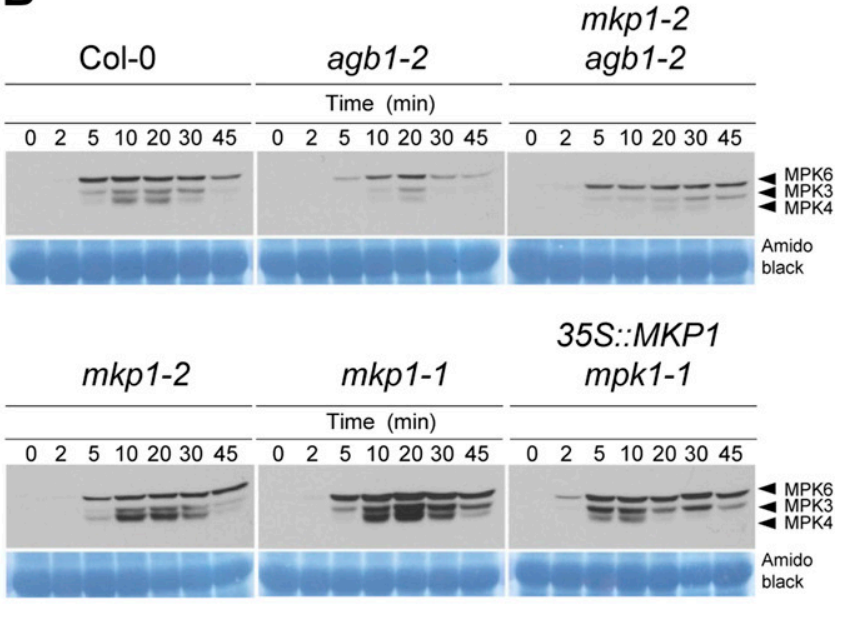

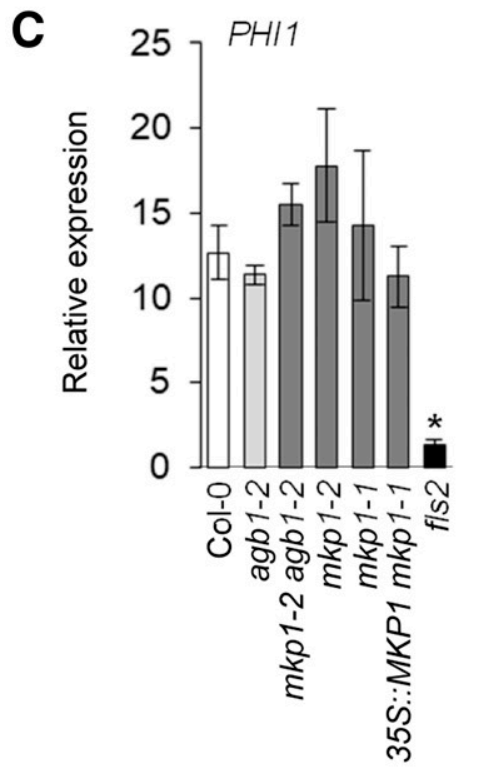
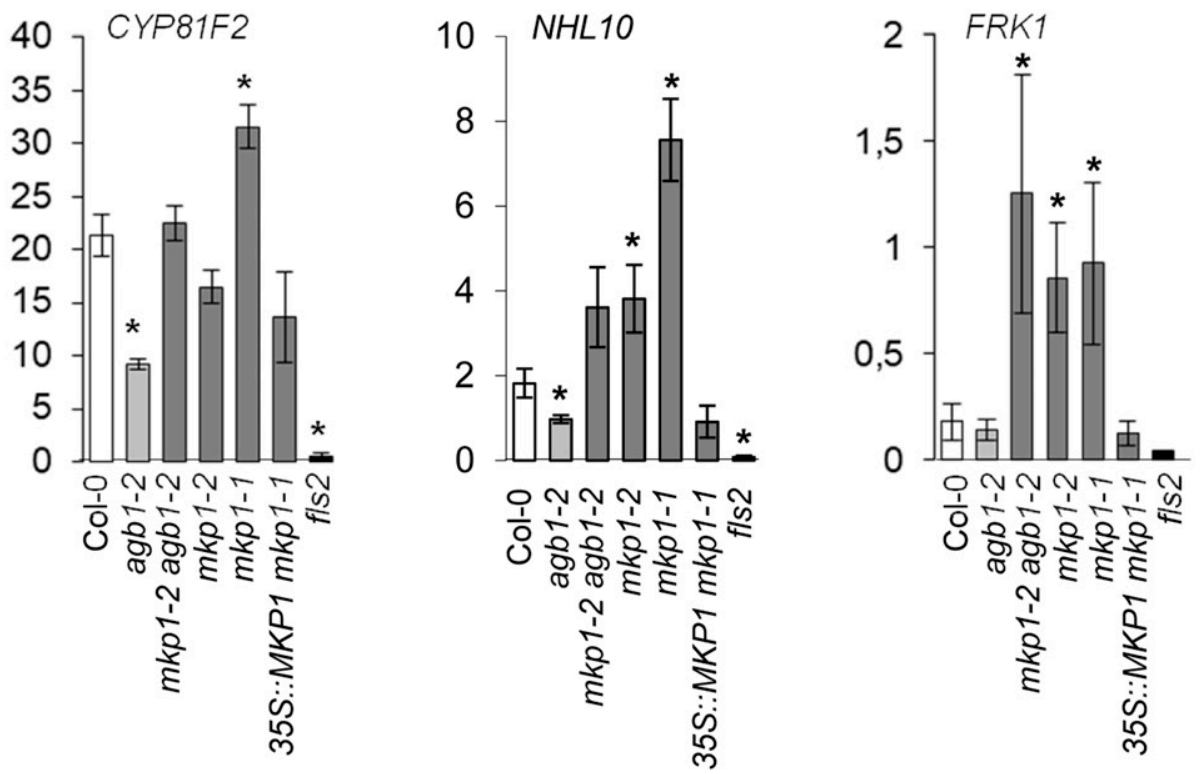

Fig. 3. Mutation in $M K P 1$ restores agbl-2 defective immune responses. A, $\mathrm{H}_{2} \mathrm{O}_{2}$ production after $100 \mathrm{nM}$ flg 22 treatment, measured in a luminol-based assay using leaf discs from 4-week-old plants of the indicated genotypes. Data represented are RLU (relative luminescence units) measured over time from one of three experiments performed, all with similar results. B, Activation of mitogen-activated protein kinases 6, 3, and 4 (MPK6, MPK3, MPK4) in 12-day-old seedlings of the indicated genotypes after treatment with $1 \mu \mathrm{M}$ of flg22. Phosphorylation was determined at the indicated timepoints (min) by immunodetection, using the anti-pTEpY antibody. Amido black-stained membranes are shown for equal loading. Data presented comes from one representative experiment of three performed, all with similar results. C, Expression analyses of microbe-associated molecular pattern-induced genes in 12-day-old seedlings from the indicated genotypes after treatment with $1 \mu \mathrm{M}$ flg22 for $30 \mathrm{~min}$. Expression levels are relative to the $U B C 21$ gene expression. Values are means of two independent experiments ( \pm standard error, $n=4$ ). Asterisks indicate significant differences from Col-0 plants (Student's $t$ test, $P<0.05$ ). 
only partially restored in $m k p l-2$ agbl-2 plants. Specifically, $m k p 1-1$ and $m k p 1-2$ plants exhibited an enhanced ROS production in response to flg22 treatment in comparison with Col0 wild-type plants (Fig. 3A). In addition, the impairment of agb1-2 ROS production after elicitation with elf18, an additional bacterial MAMP (Ishikawa 2009), was also partially restored to wild-type levels in mkpl-2 agbl-2 plants (Supplementary Fig. S5), and ROS production in mkpl-1 and mkpl-2 was higher than in Col-0 plants upon treatment with chitin, a fungal MAMP (Cao et al. 2014) (Fig. 4). Therefore, inactivation of MKP1 restores ROS production in agb1-2 plants upon MAMP perception, indicating that MKP1 negatively regulates ROS production during plant immunity. Accordingly, in the complementation plants $35 S:: M K P 1 \mathrm{mkpl}-1$, the enhanced ROS production of $m k p l$ was restored to Col-0 levels upon flg22 treatment (Fig. 3A).

We also monitored MAPK phosphorylation after flg22 treatment (Fig. 3B) and found that agbl-2 plants qualitatively exhibited a clear impairment in MAPK phosphorylation that was partially restored to wild-type levels in the presence of the mkp1-2 mutation. Loss of MKP1 function has been associated with increased levels of active MPK6 and MPK3 (Bartels et al. 2009) and, as expected, in $m k p 1-1$ and $m k p 1-2$ plants, the crossreacting bands of phospho-MPK6 and MPK3 and also of MPK4 were stronger than those observed in wild-type plants (Fig. 3B).
Genetic complementation of $m k p 1-1$ plants with ectopic $M K P 1$ restored MPK phosphorylation levels to those observed in Col-0 plants. Also, expression of MAMP-regulated genes (e.g., CYP81F2, NHL10, and FRK1) (Boudsocq et al. 2010) was enhanced in mkpl-2 agbl-2 plants compared with $a g b 1-2$ and in mkpl-1 plants compared with Col-0 (Fig. 3C). Together, these data indicate that $m k p l$ qualitatively restores the defective MAMP-triggered immune responses of agbl-2.

\section{The enhanced MAMP-triggered ROS production of $m k p 1$ plants is dependent on RBOHD activity.}

To determine whether the elevated levels of ROS produced in mkpl-1 and mkpl-2 mutants upon MAMP treatment was dependent on $R B O H D$, we generated $m k p 1-1$ rbohD and $m k p 1-2$ rbohD double mutants and tested their ROS production upon flg22 or chitin treatment. As shown in Figure 4A and B, mkpl-1 rbohD and $m k p l-2$ rbohD double mutants, like rbohD plants, were unable to produce ROS, which contrasted with the elevated ROS production observed in $m k p l-1$ and $m k p 1-2$ plants. These results demonstrated that the enhanced ROS production observed in $m k p l$ mutants is produced by the NADPH oxidase RBOHD. To confirm the origin of this ROS, $m k p 1-1$ and $m k p 1-$ 2 were also crossed with a transgenic line overexpressing $R B O H D$ under the control of the 35S promoter of Cauliflower mosaic virus (35S::RBOHD) (Kadota et al. 2014), and ROS
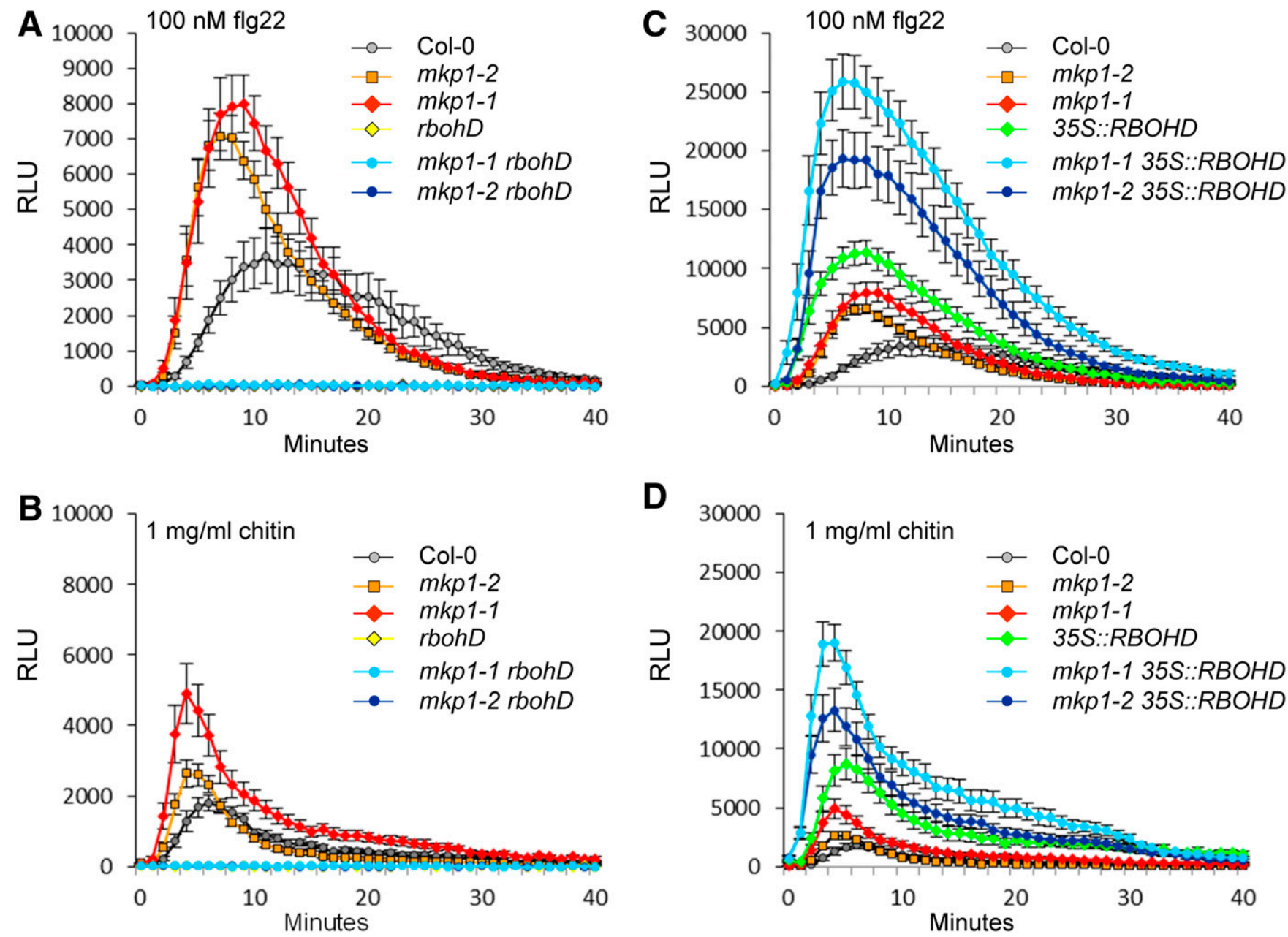

Fig. 4. Enhanced reactive oxygen species (ROS) production observed in $m k p l$ mutants is $R B O H D$-dependent. $\mathrm{H}_{2} \mathrm{O}_{2}$ production after microbe-associated molecular pattern treatment, measured in a luminol-based assay using leaf discs from 4-week-old plants of the listed genotypes. A, and $\mathbf{C}$, Discs were treated with $100 \mathrm{nM}$ flg22. B, and $\mathbf{D}$, The elicitor was chitin at $1 \mathrm{mg} / \mathrm{ml}$. rbohD and combinatory mutants with $r b o h D$ display no ROS production in these assays. Relative light units (RLU) were measured over a period of $40 \mathrm{~min}$. Values are means \pm standard error $(n=12)$. The experiment was repeated three times with similar results. 
production was again tested upon flg22 or chitin treatment. $35 S:: R B O H D$ mkpl-1 and 35S::RBOHD mkpl-2 plants produced ROS faster and to a greater extent (two- to threefold) than the 35S::RBOHD line in Col-0 background, which gave an enhanced response compared with wild-type plants (Col-0) and the individual $m k p l-1$ and $m k p l-2$ mutants (Fig. 4C and D). These results confirm that the higher levels of ROS produced in mkpl mutant plants in response to MAMPs are RBOHD-dependent and suggest that MKP1 negatively regulates RBOHD activity at different levels.

To gain insights into the regulation of RBOHD function mediated by MKP1, we determined whether impairing ROS production in $m k p l-2$ impacts $m k p l$-associated developmental phenotypes. Therefore, we grew, in parallel, $m k p l-2$ rbohD double mutant plants together with Col-0 plants and the parental lines, and we compared their rosette size at 3, 4, and 5 weeks after sowing (Supplementary Fig. S6). $m k p 1-2$ plants were smaller than Col-0 plants throughout the period analyzed, whereas rosette size of rbohD plants was comparable to that of wild-type plants. Interestingly, the $m k p l-2$ rbohD double mutant showed an intermediate size between Col-0 and mkpl-2. Since alterations of the SA pathway were shown to diminish the mkpl-1 aberrant phenotypes (Bartels et al. 2009), we also crossed $m k p 1-2$ to $N a h G$ (Delaney et al. 1994) and sid2 (Wildermuth et al. 2001). As expected, $m k p l-2 ~ N a h G$ and $m k p 1-2$ sid 2 double mutants displayed a rosette size comparable to that of the individual $N a h G$ and sid2, respectively, which did not differ from that of Col-0 wild-type plants. Taken together, these data suggest that the small size of $m k p l-2$ is largely dependent on the SA pathway and partially dependent on ROS produced by RBOHD, suggesting a function of ROS and SA in balancing growth/defense tradeoffs in $m k p l-2$ plants.

\section{The transcriptional level of $\mathrm{RBOHD}$ is enhanced in $m k p 1$ plants.}

The differential ROS production upon MAMP treatment in $m k p 1$ plants led us to determine whether RBOHD activity could be also regulated transcriptionally in $m k p l$ plants. Notably, expression of the $R B O H D$ gene was constitutively enhanced in adult plants harboring the $m k p l$ null mutation (Fig. 5A). To further characterize this transcriptional regulation, $p D:: L U C$ lines harboring the promoter of the RBOHD gene fused to a luciferase $(L U C)$ gene (Morales et al. 2016) were crossed with $m k p l-2$ and $m k p l-1$ alleles and the transcriptional activation of $R B O H D$ gene upon MAMP and pathogen ( $P$. cucumerina $\mathrm{BMM}$ ) infection was tested. As shown in Figure $5 \mathrm{~B}$, the transcriptional regulation of $R B O H D$ gene upon flg22 treatment was enhanced in $m k p l-2$ and $m k p l-1$ backgrounds in comparison with $p D:: L U C$ in Col-0. Moreover, we tested the in-vivo transcriptional activation of $R B O H D$ in $m k p l-2$ and $m k p l-1$ lines upon infection with $P$. cucumerina $\mathrm{BMM}$ and found that it was also enhanced in comparison with $p D:: L U C$ (Col-0) and that this activation was reverted in the complementation lines (pD::LUC 35S::MKPl mkpl) (Fig. 5C).

\section{MKP1 and RBOHD are components of immune pathways required for resistance to $P$. cucumerina $\mathrm{BMM}$.}

mkpl mutants are more resistant to the necrotrophic $P$. cucumerina BMM than Col-0, indicating that MKP1 is a negative regulator of disease resistance. On the other hand, ROS produced by RBOHD has been suggested to contribute to resistance to this necrotrophic fungus because $r b o h D$ is slightly more susceptible to this fungus than Col-0, and this susceptibility phenotype is enhanced in the rbohD rbohF double mutant (Torres et al. 2013). Based on these previous data, we tested epistasis between $M K P 1$ and $R B O H D$ by analyzing $P$. cucumerina BMM growth in the $m k p 1-1$ rbohD and $m k p 1-2$
rbohD double mutants and mkpl-1 35S::RBOHD and mkpl-2 $35 S:: R B O H D$ lines sprayed with a spore suspension of this fungus. Fungal biomass quantification by qPCR revealed that susceptibility to $P$. cucumerina $\mathrm{BMM}$ of the $m k p 1-1$ rbohD and mkpl-2 rbohD double mutants was comparable to that of the parental lines $m k p 1-1$ and $m k p 1-2$, which supported less fungal growth than did Col-0 (Fig. 6). Despite the fact that ectopic expression of $R B O H D$ (35S::RBOHD plants) conferred enhanced fungal growth, the mkpl-1 35S::RBOHD and $m k p 1-2$ $35 S:: R B O H D$ lines, like the $m k p 1-1$ and $m k p l-2$ parental lines, displayed reduced fungal progression compared with Col-0. Taken together, these results indicate that there is an epistatic, genetic interaction between $m k p l$ mutants and $r b o h D$ in the control of Arabidopsis resistance response to P. cucumerina $\mathrm{BMM}$, that ROS production is not fully required for $\mathrm{mkpl-}$ mediated resistance to $P$. cucumerina BMM, and that other defensive pathways activated in $m k p l$ might be sufficient to confer enhanced resistance to the fungus, as has been previously reported (Berrocal-Lobo et al. 2002; Sanchez-Vallet et al. 2010, 2012).

mkp1-2 plants show constitutive activation of the SA and the JA and ethylene (ET) defense pathways and accumulate a diverse set of antimicrobial metabolites.

To explain $m k p l$ enhanced resistance phenotypes to different pathogens, we determined, in agbl-2, mkpl-2 agb1-2, mkpl-2, $m k p 1-1$, and Col-0, the expression of marker genes of SA $(P R 1)$, ET (PR4), ET + JA (PDF 1.2) signaling, and of camalexin synthesis (e.g., PAD3). As shown in Figure 7A, in adult (24-day-old) plants, all these genes were up-regulated in $m k p 1-2$ agbl-2, $m k p 1-2$, and $m k p 1-1$ in comparison with Col-0 and agb1-2 plants, as previously reported (Bartels et al. 2009; Delgado-Cerezo et al. 2012). The upregulation of these defensive marker genes in mkpl-1 was suppressed by complementation in the $35 S: \because M K P 1 \mathrm{mkpl}-1$ plants, which showed expression levels of these genes similar to those of wild-type plants (Fig. 7A). Noteworthy, the induction of some of these signaling pathways is age-dependent, as the expression of marker genes mediated by SA and JA are not up-regulated in 12-day-old $\mathrm{mkpl}$ seedlings that do not show lesions in leaves (Fig. 2; Supplementary Fig. S7).

mkpl-1 plants have been described to differentially accumulate some metabolites that contribute to expression of Pseudomonas syringae pv. tomato virulence factors (Anderson et al. 2014). Global metabolomics analysis of untreated fourweek-old $m k p l-2$ and Col-0 plants revealed more than 170 metabolites showing significant differential accumulation in mkp1-2 in comparison with Col-0 plants (Fig. 7B). Highly accumulated metabolites in $m k p l-2$ include some antimicrobial compounds of the glucosinolate pathway or camalexin (as described previously) (Anderson et al. 2014) as well as defenseassociated metabolites, like SA, gentisate, or pipecolate (Fig. $7 \mathrm{~B}$ and $\mathrm{C}$ ), which display relevant functions during activation of disease resistance responses and accumulate during pathogen infection (Campos et al. 2014; Chen et al. 2018; Hartmann et al. 2018; Seyfferth and Tsuda 2014; Wang et al. 2018a). The constitutive expression of defensive genes and the enhanced accumulation of these metabolites in $m k p l-2$ plants could explain the broad-spectrum disease resistance of this mutant.

\section{DISCUSSION}

\section{Mutations in MKP1 suppress agb1-2 susceptibility to different pathogens.}

Heterotrimeric $\mathrm{G}$ protein constitutes an important node during MTI activation, since mutation in some of their components block many MTI responses and rend plants extremely 
vulnerable to a wide variety of pathogens (Brenya et al. 2016; Ishikawa 2009; Llorente et al. 2005; Lorek et al. 2013; Torres et al. 2013; Trusov et al. 2006). In a suppressor screening based on susceptibility to the necrotrophic fungus $P$. cucumerina
BMM of the $a g b 1-2$ mutant, impaired in the $\beta$-subunit of heterotrimeric $\mathrm{G}$ protein, we isolated the $\mathrm{sgbl0}$ mutant and uncovered $M K P 1$ as an important component of MTI responses (Fig. 1). Although, in $s g b 10$, an additional mutation in the

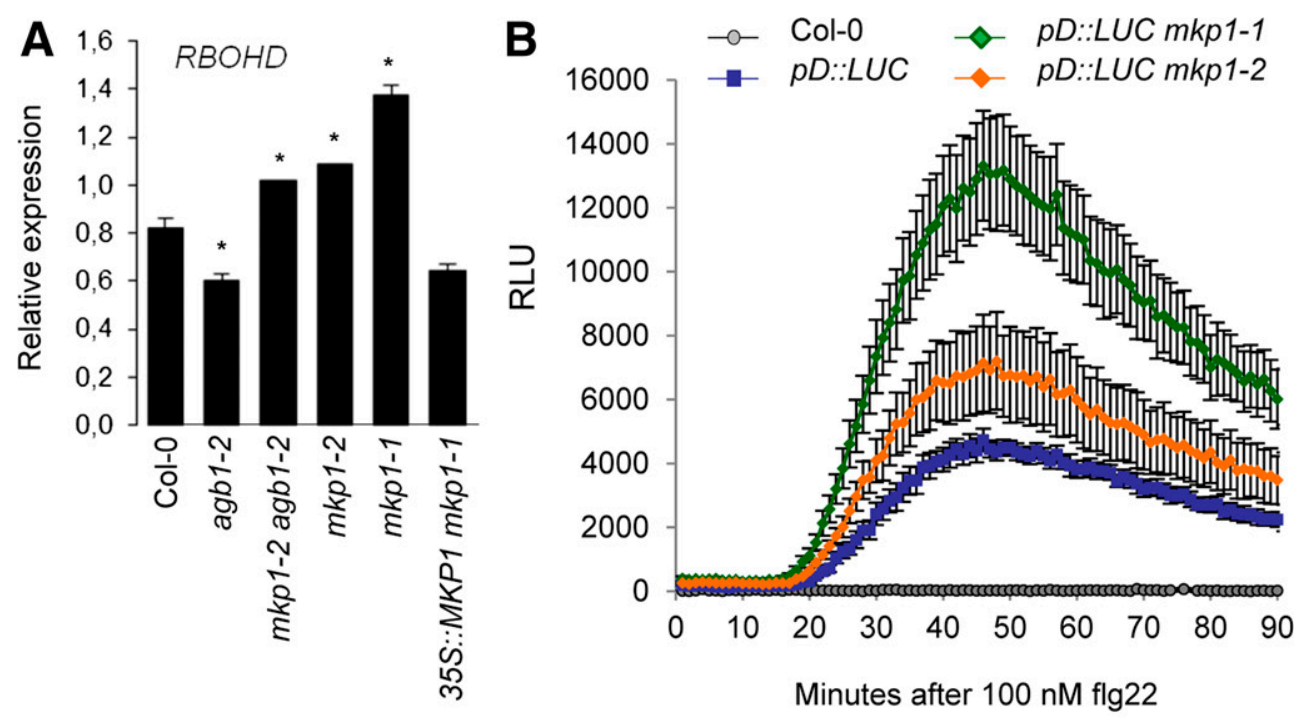

C $p D:: L U C$
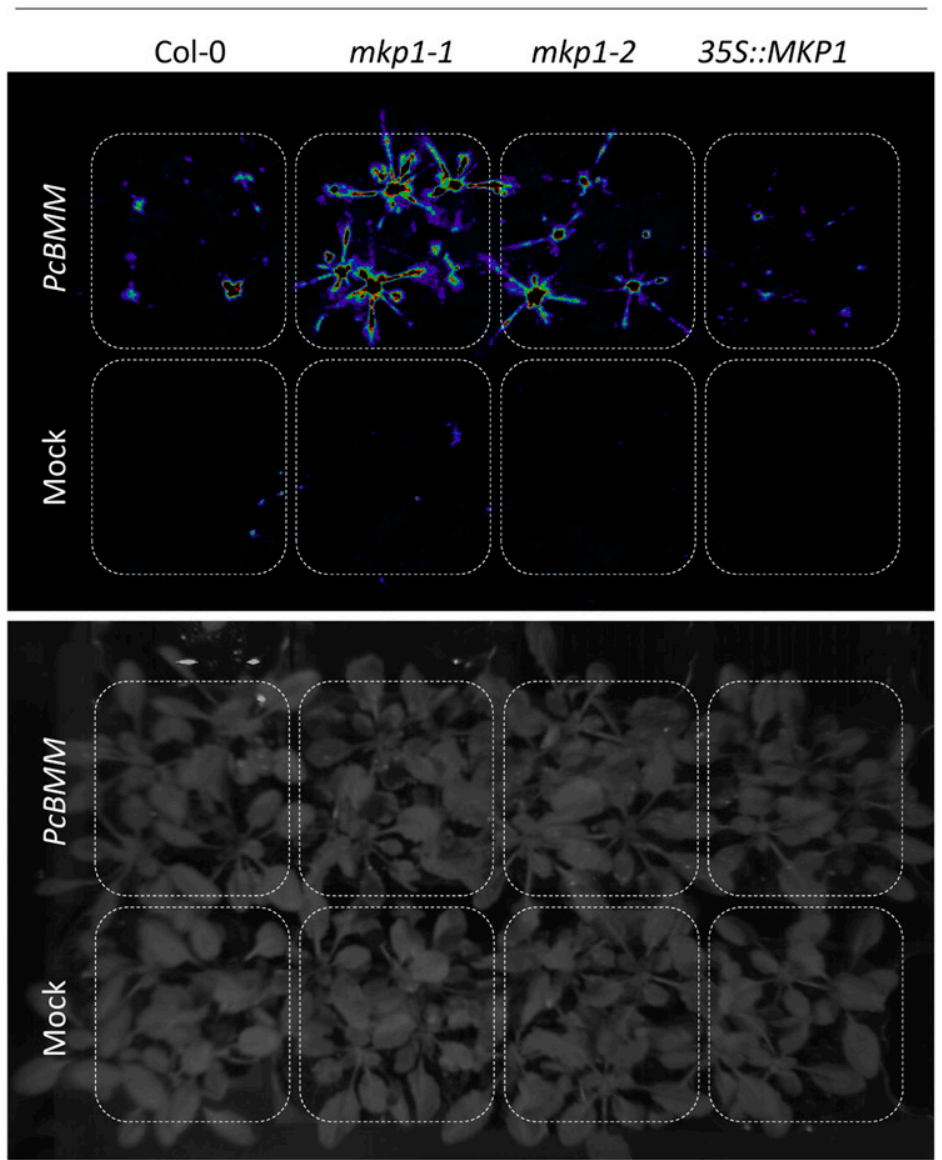

Fig. 5. Enhanced $R B O H D$ expression in $m k p l$ mutants. A, Determination of $R B O H D$ expression by quantitative reverse transcription-polymerase chain reaction in 24-day-old plants of the indicated genotypes. RBOHD gene expression was normalized using $U B C 21$ gene as endogenous control. Data represent the average of two biological replicates (mean \pm standard error [SE]). Asterisks indicate statistically significant differences compared with Col-0, according to Student's $t$ test $(P<0.05)$. B, Luciferase activity of 4 -week-old $p D:: L U C$ plants, in the indicated backgrounds, after treatment of leaf discs with $100 \mathrm{nM}$ flg22. Relative light units (RLU) were measured over a period of $90 \mathrm{~min}$. Values are averages $\pm \mathrm{SE}(n=8)$. C, In vivo bioluminescence generated by 3 -week-old $p D:$ : $L U C$ plants under different genotypes $24 \mathrm{~h}$ after spraying with Plectosphaerella cucumerina BMM $\left(4 \times 10^{6}\right.$ spores $\left./ \mathrm{ml}\right)$. All experiments were repeated at least three times with similar results. 
proline transporter AtProT2 (Lehmann et al. 2011) was localized in the same genomic region as $m k p 1-2$, AtProT2 mutation was dismissed as the potential mutation causing the $s g b 10$ phenotype because atprot2-3 plants did not show enhanced resistance to $P$. cucumerina BMM, in contrast to $m k p l$ alleles tested. Because $m k p l$ is also able to suppress $a g b 1-2$ susceptibility to the hemibiotrophic bacterium Pseudomonas syringae pv. tomato DC3000 (Fig. 2) (Anderson et al. 2011; Bartels et al. 2009) and the oomycete $H$. arabidosidis Noco2, we conclude that MKP1 is a broad negative regulator of the resistance

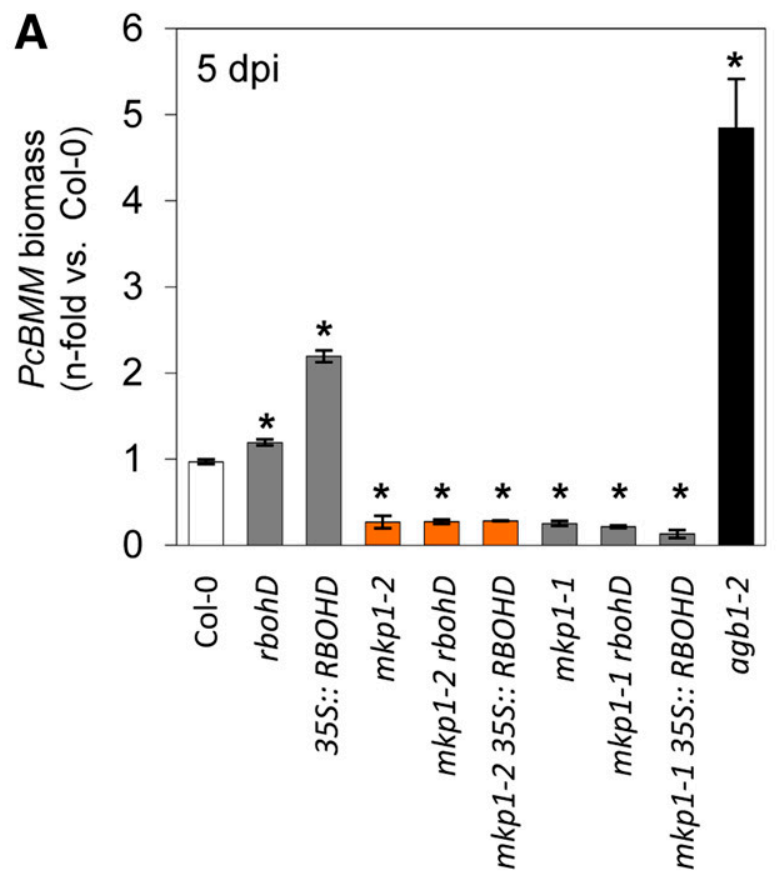

B

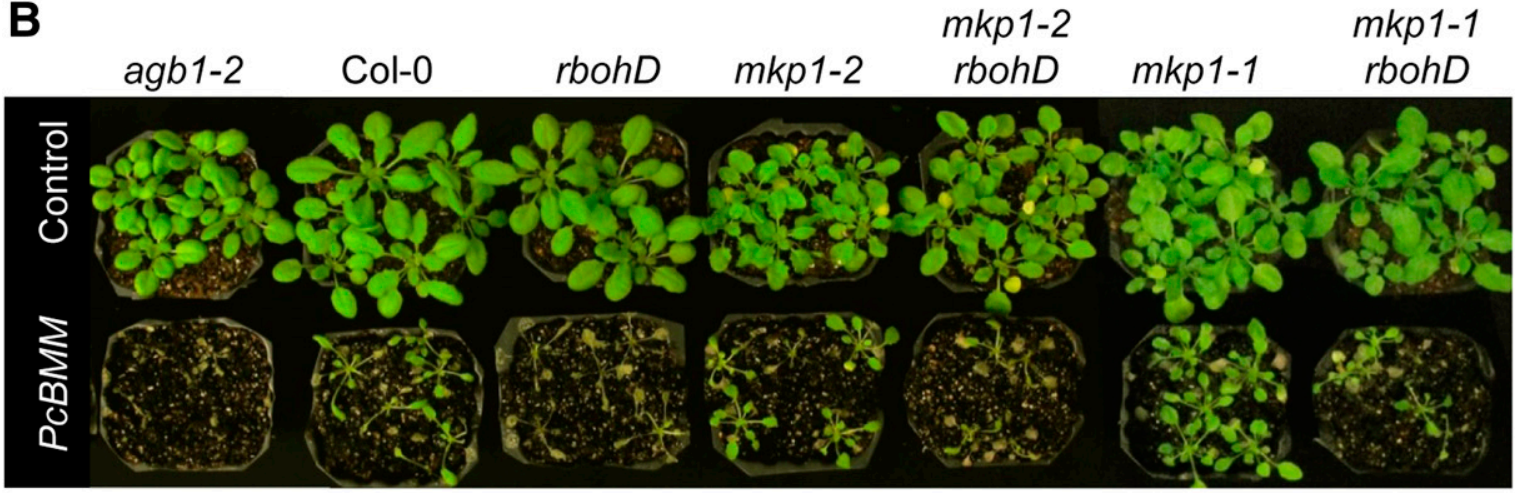

C

$m k p 1-2$

$m k p 1-1$

$35 S:: R B O H D \quad m k p 1-2 \quad 35 S:: R B O H D$ mkp1-1 $35 S:: R B O H D$

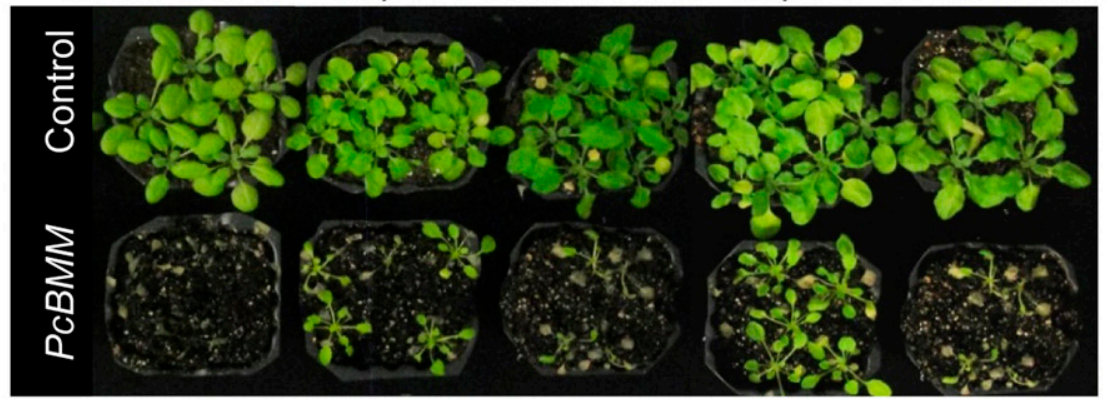

Fig. 6. $m k p 1$ mutants are epistatic over $r b o h D$ and $35 S:: R B O H D$ on the response to Plectosphaerella cucumerina BMM. A, P. cucumerina BMM biomass quantification in plants of the listed genotypes by quantitative polymerase chain reaction, at 5 days postinoculation (dpi), with a suspension of $4 \times 10^{6}$ spores $/ \mathrm{ml}$ of the fungus. Specific primers of $P$. cucumerina BMM $\beta$-TUBULIN and Arabidopsis UBC21 genes were used. Values are represented as average ( \pm standard error) of the $n$-fold increase compared with Col-0 plants. Asterisks indicate values statistically different from Col- 0 , according to Student's $t$ test $(P<0.05)$. B, and $\mathbf{C}$, Macroscopic disease symptoms of the indicated genotypes at 10 dpi. Top, control plants; bottom, P. cucumerina BMM-sprayed plants. 
response to different pathogens, which is consistent with some of its previously described functions (Anderson et al. 2011; Bartels et al. 2009). Interestingly, $m k p 1-2$ does not restore to wild-type levels different developmental phenotypes associated with the $a g b 1-2$ mutation. The uncoupled disease resistance and developmental phenotypes of $m k p l-2$ agbl-2 have also been reported for other $a g b 1-2$ suppressors, like eskimol/sgb11, which restores the defective immune responses of agbl-2 but not its developmental-associated phenotypes (Escudero et al. 2017). These data suggest that Arabidopsis heterotrimeric $\mathrm{G}$ protein complex might regulate developmental and defense responses through different mechanisms. This
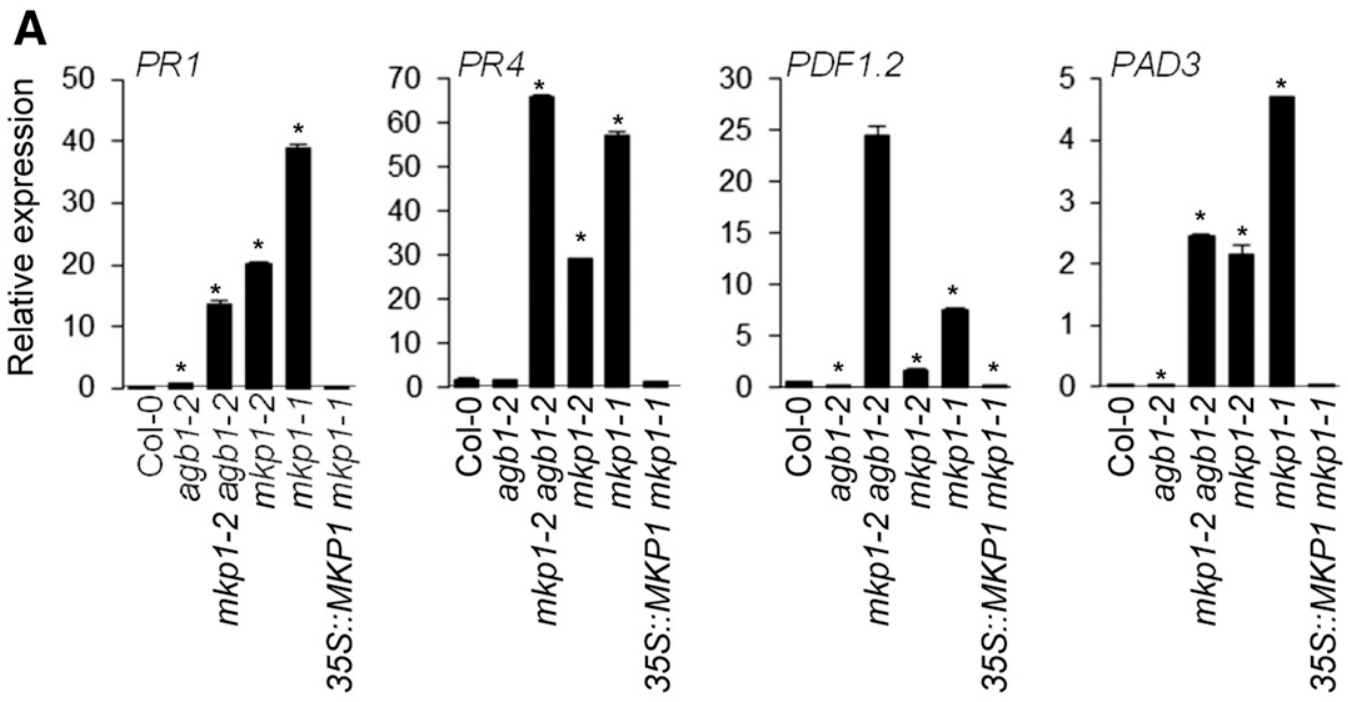

B

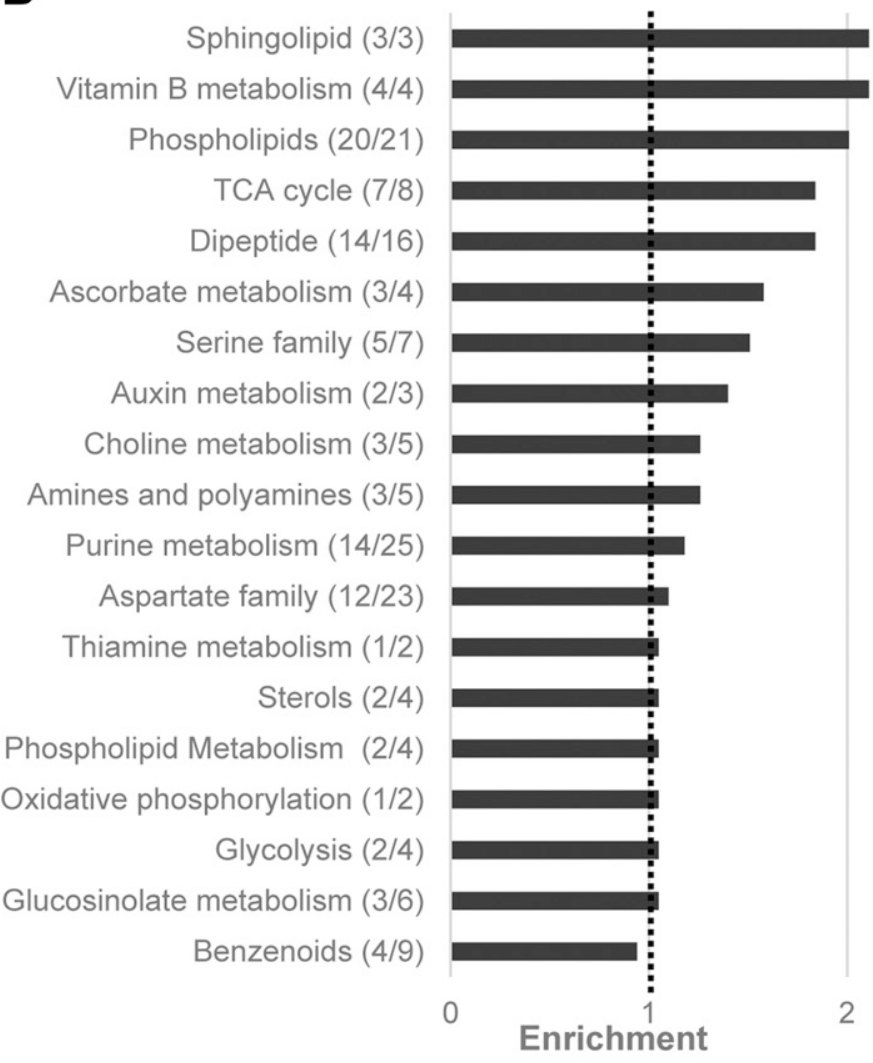

C

\begin{tabular}{|c|c|c|}
\hline \multirow{2}{*}{ Pathway } & Biochemical name & $\begin{array}{c}\text { Fold change } \\
\text { (mkp1-2/WT) }\end{array}$ \\
\hline \multirow{2}{*}{$\begin{array}{c}\text { Glucosinolate } \\
\text { metabolism and } \\
\text { phytoalexin }\end{array}$} & Camalexin & 81.28 \\
\cline { 2 - 3 } & Indole-3-carboxylic acid & 7.68 \\
\cline { 2 - 3 } & Sulforaphane-cys & 2.33 \\
\cline { 2 - 3 } & Sulforaphane-cys-gly & 1.91 \\
\hline \multirow{3}{*}{ Benzenoids } & Gentisate & 7.98 \\
\cline { 2 - 3 } & Gentisic acid-5-glucoside & 2.92 \\
\cline { 2 - 3 } & Salicylate & 2.19 \\
\cline { 2 - 3 } & Phenylacetylglutamate & 2.96 \\
\hline \multirow{2}{*}{ Phenylpropanoids } & Lariciresinol & 4.42 \\
\cline { 2 - 3 } & Coniferin & 4.04 \\
\hline Aspartatefamily & Pipecolate & 8.44 \\
\hline Alkaloids & Salidroside & 2.17 \\
\hline Ethylene & Cyano-alanine & 3.06 \\
\hline metabolism & \multicolumn{2}{|c|}{} \\
\hline
\end{tabular}

Fig. 7. Mutations in $M K P 1$ positively activate defense gene expression and accumulation of secondary metabolites. A, Expression of the indicated defenserelated genes $(P R 1, P R 4, P D F 1.2$, and $P A D 3)$ was determined by quantitative reverse transcription-polymerase chain reaction in tissues from 24-day-old untreated plants of the indicated genotypes. Expression levels were normalized to Arabidopsis UBC21 gene. Data represent the average ( \pm standard error) of a biological replicate. This experiment has been performed three times with similar results. Asterisks indicate significant differences with Col-0 plants, according to Student's $t$ test $(P<0.05)$. B, Enrichment of metabolic pathways present in 4-week-old $m k p l-2$ plants compared with Col- 0 , calculated as the number of experimentally regulated compounds (Student's $t$ test, $P<0.05$ ) relative to all detected compounds in a pathway compared with the total number of experimentally regulated compounds relative to all detected compounds (321 metobolites) in the study (Supplementary Tables S4 and S5). C, Table depicting some of the secondary metabolites related to defense enriched in $m k p 1-2$ plants compared with Col- 0 plants. Numbers indicate fold change abundance in $m k p 1$ 2 compared with Col-0. Defense-related metabolites are highlighted in gray. 
differential function may rely on the ability of heterotrimeric $G$ protein subunits to form complexes with a wide range of proteins in different contexts (Klopffleisch et al. 2011; Liang et al. 2016; Wang et al. 2018b; Yuan et al. 2017). This dual signaling capability of AGB1 has also been reported for other important signaling nodes in plant immunity, such as the ERECTA RLK or the MAP3K YODA (Jordá et al. 2016; Sopeña-Torres et al. 2018). The fact that $m k p l-2$ suppresses agbl-2 phenotypes indicate that both proteins act on the same pathway, although this does not necessarily mean that MKP1 directly acts on or interacts with AGB1. Thus, MKP1 was not among the proteins identified in G-protein interactome analyses (Klopffleisch et al. 2011), suggesting that AGB1 and MKP1 do not form a protein complex.

\section{MKP1 acts as a broad negative regulator of plant immune responses.}

MKP1 belongs to the group of Ser/Thr and Tyr DSPs that, in the Arabidopsis genome, comprises a family of 22 members. Among this family, there are five members, including MKP1, that contain a DSP extended active site motif, characteristic of mammalian MPKs (Bartels et al. 2010). MKP1 appears to dephosphorylate and inactivate several MAPKs, with the strongest interaction with MPK6 (Bartels et al. 2009; Ulm et al. 2002). In addition, MPK6 phosphorylates and increases the stability and the phosphatase activity of MKP1 (González Besteiro and Ulm 2013), suggesting the existence of a feedback loop that attenuates the activation of MAPKs (Jiang et al. 2017a; Park et al. 2001). Thus, MKP1 mediates a wide variety of functions in plants: i) as a positive regulator in DNA damage response, since $m k p l$ is hypersensitive to genotoxic stress conferred by several DNA-damaging agents; ii) as a negative regulator of stress responses, because the mutant is more resistant to abiotic (salinity) and biotic (Pseudomonas syringae) stresses; and iii) promoting stomatal cell fate transition by controlling MAPK activation downstream of YDA MAP3K (Anderson et al. 2011, 2014; Bartels et al. 2009; Jiang et al. 2017a; Tamnanloo et al. 2018; Ulm et al. 2001, 2002).

Our analyses indicate that, as opposed to the role of AGB1, MKP1 acts a negative regulator of plant immune responses because the double $m k p 1-2$ agbl-2 mutant partially restores ROS production in response to bacterial and fungal MAMPs (Fig. 3A) as well as MAPK cascades and defense-gene activation (Fig. 3B and $\mathrm{C}$ ). This agrees with previous reports showing that, under bacterial attack, MKP1 interacts with different elements of the MAPK cascade, including MPK3, MPK4, and MPK6, acting as negative regulator of defensive responses by suppressing SA biosynthesis, ROS production, and the upregulation of some defense marker genes (Anderson et al. 2011; Bartels et al. 2009; Katou et al. 2007). MKP1 has been proposed to act as a negative regulator of the MPK (particularly MPK6) signaling pathways, because some of the enhanced defense responses are suppressed in the double $m \mathrm{kpl}$ mkp6 (Anderson et al. 2011). However, misregulation of the MAPKs alone was not sufficient to explain all the alterations of downstream responses to treatments with MAMP (Anderson et al. 2011). In addition, mutants in these MAPKs do not abrogate ROS production in response to MAMPs (Galletti et al. 2011; Mersmann et al. 2010), though this could be explained by the functional redundancies of MAPKs. These data suggest that MKP1 must have additional targets than MPKs, particularly in relation to its function in the regulation of ROS production, and we propose, here, that RBOHD is one of these novel targets.

\section{MKP1 negatively regulates RBOHD-dependent ROS production in response to MAMPs.}

Phosphorylation cascades induced by pathogens are associated with ROS production, although these signals appear to work both upstream and downstream of each other in different contexts (Asai et al. 2002; Samuel et al. 2005). For example, overexpression of the constitutive active MAPK kinase MKK4 induces ROS production in association with an HR-like response (Ren et al. 2002; Takahashi et al. 2007). Moreover, downstream targets of MKK4, such as MPK3 and MPK6, activate RBOHD-dependent ROS, as revealed by studies with a Pseudomonas syringae effector that targets these kinases (Zhang et al. 2007). In our study, the elevated ROS production after MAMP treatment in the $m k p l$ plants gets enhanced by overexpressing $R B O H D$ but is compromised by rbohD mutation (Fig. 4). Moreover, the rbohD mutation partially suppresses the aberrant growth displayed by $m k p l-2$. These data suggest that RBOHD is a downstream target of MKP1 after pathogen attack and MAMP perception and that this phosphatase negatively regulates ROS production by RBOHD. However, the evaluation of $P$. cucumerina BMM infection performed on the combinatory lines indicate that the $\mathrm{mkpl}$ mutants are epistatic over the lines that abrogate or overexpress $R B O H D$ (Fig. 6), but also means that additional defensive pathways overactivated in $m k p l$ plants are sufficient to compensate the deregulation of ROS production and to contribute to the enhanced resistance to $P$. cucumerina BMM.

Activation of ROS production by Arabidopsis NADPH oxidases is largely achieved by posttranslational modifications at the N-terminus of these enzymes (Kadota et al. 2015). For example, RBOHD, the main NADPH oxidase responsible for most ROS in Arabidopsis (Torres and Dangl 2005), is rapidly phosphorylated and activated by $\mathrm{Ca}^{2+}$-dependent kinases (Dubiella et al. 2013; Kobayashi et al. 2007) and by the cytoplasmic kinase BIK1 upon formation of the PRR complex after MAMP perception (Kadota et al. 2014; Li et al. 2014). This ROS production is transient and, because the mkpl mutants display faster and elevated levels of ROS production after MAMP treatment (Figs. 3A and 4), we speculate that MKP1 controls the phosphorylation state of this oxidase to downregulate its activity. However, the higher level of $R B O H D$ transcript observed in mkpl mutant background and the upregulation of its promoter by MAMPs and pathogens (Fig. 5) suggest that MKP1 also exerts a control of ROS production by regulating the expression of $R B O H D$. Transcriptional control of the plant NADPH oxidases is required to specify their function and to achieve the high amount of $\mathrm{H}_{2} \mathrm{O}_{2}$ observed after pathogen recognition (Morales et al. 2016). Interestingly, MAPKs activate WRKY transcription factors that bind to the promoter of the ortholog of RBOHD in Nicotiana benthamiana, resulting in a sustained ROS burst (Adachi et al. 2015). Therefore, MKP1 may limit the action of phosphorylation cascades that control the level of NADPH oxidases responsible for this ROS burst in response to pathogens.

Our essays with $P$. cucumerina BMM revealed that both rbohD and $35 S:: R B O H D$ support enhanced pathogen growth in comparison with control plants (Fig. 4). Thus, RBOHDdependent ROS is important for resistance against this pathogen, but both increase and decrease of ROS signals seem to alter the outcome of resistance. The most plausible explanation is that compensatory mechanisms balance the defense response mediated by ROS signals. Indeed, despite the clear link established between NAPDH oxidases and plant disease resistance (Torres et al. 2002), the requirement for these proteins in defense is not habitually clear from the study of mutants, which often do not display strong alteration in pathogen growth (Marino et al. 2012). For example, although, the mutant rbohD itself just supports slightly enhanced pathogen growth in comparison with wild-type plants (Fig. 4) (Marino et al. 2012), the function of RBOHD in MTI is clear from the enhanced susceptibility to bacteria of lines expressing $R B O H D$ with point 
mutations in its regulatory sites (Kadota et al. 2014). Also, the same oxidases can act as positive or negative regulators of pathogen growth and cell death in different context (Marino et al. 2012; Pogany et al. 2009; Torres et al. 2002, 2005). All these data point to the existence of compensatory mechanisms acting after alteration of ROS homeostasis.

\section{Accumulation of some defense-related metabolites could explain the enhanced resistance of $m k p l$.}

mkpl was shown to exhibit constitutive defense responses and aberrant growth associated to the accumulation of SA (Bartels et al. 2009). These growth defects are apparent in the Col-0 background but not in the Ws accession and are linked to the presence, in that genotype, of the resistance gene $S N C 1$, encoding a toll interleukin 1 receptor-nucleotide bindingleucine-rich repeat protein that triggers defense gene expression (Anderson et al. 2011; Bartels et al. 2009). Also, although abrogation of the SA pathway in SA-deficient lines suppresses the enhanced resistance to Pseudomonas syringae pv. tomato DC3000 in mkpl-1 in Col-0 background (Bartels et al. 2009), lack of SA accumulation and $P R 1$ expression observed in the same mkpl-1 mutation in Ws does not compromise the enhanced resistance in this background (Anderson et al. 2011). We also observed that SA-dependent as well as JA and ET marker genes are only constitutively up-regulated in $m k p l-1$ plants at some developmental stages (Fig. 7A), suggesting that activation of SA and other hormone-related defensive pathways might contribute to resistance to some pathogens (e.g., P. cucumerina $\mathrm{BMM}$ and Pseudomonas syringae pv. tomato [Figs. 1 and 2A]) but would not be a prerequisite for resistance to other pathogens (e.g., H. arabidosidis [Fig. 2B]). On the other hand, the faster and stronger activation of ROS production as well as MAPK activation in response to MAMPs (Fig. 3A and $\mathrm{B}$ ) suggests that $m k p l$ is able to mount a more efficient disease resistance response upon pathogen infection and MAMP detection that would explain the restoration of MTIdefective responses of agb1-2. Our metabolomics study on mkp1-2 revealed that changes in some defense-related metabolites could account for the enhanced resistance of this mutant. For example, untreated $m k p 1-2$ displayed quite elevated levels of antimicrobial metabolites, like camalexin and glucosinolates, in comparison with Col-0 wild-type plants. Moreover, defense-associated metabolites like SA, gentisate, or pipecolate (Fig. 7B and C), which display relevant functions during activation of disease resistance responses (Campos et al. 2014; Chen et al. 2018; Hartmann et al. 2018; Seyfferth and Tsuda 2014; Wang et al. 2018a), also accumulate in $m k p 1-2$, probably contributing to $m k p l-2$ immunity. The elevated levels of these compounds in mkpl-2 could explain the aberrant phenotypes displayed by this mutant (Fig. 2) (Anderson et al. 2014; Bartels et al. 2009) and the enhanced resistance to $P$. cucumerina BMM observed in $m k p l$ rbohd and $m k p 1$ 35S:RBOHD plants, since these metabolites have been shown to play a relevant role in Arabidopsis resistance to this fungus (Sanchez-Vallet et al. 2010).

In summary the data presented here provide an additional link between heterotrimeric $\mathrm{G}$ protein complex, ROS production, modulation of MTI, and disease resistance. In this regulatory network, MKP1 appears as a negative regulator of MTI that balances the degree of RBOHD activity by, probably, dephosphorylating the residues targeted by some positive MTI regulators, like BIK1 (Kadota et al. 2015), and by modulating the transcriptional regulation of the $R B O H D$ gene. These data further support a novel, key role for MKP1 in fine-tuning ROS production in plant immunity. A further characterization of the molecular mechanisms of MKP1 regulation by heterotrimeric $\mathrm{G}$ protein complex during MTI activation will contribute to determining the molecular links between recognition of MAMPs by PRRs and modulation of MTI and disease resistance responses.

\section{MATERIALS AND METHODS}

Biological materials and growth conditions.

Arabidopsis plants were grown in sterilized soil or in vitro with one-half Murashige and Skoog medium ( $1 / 2 \mathrm{MS})$, as described previously (Escudero et al. 2017). The La-0 and Ler seeds ( $e r-1$ allele in La-0 background) were provided by $\mathrm{M}$. Koornneef (Wageningen University, Wageningen, The Netherlands). The lines mkpl-1 and 35S::Pyo:MKPl in mkpl-1, named in the present work as $35 S:: M K P 1$, were provided by $\mathrm{R}$. Ulm (Department of Botany and Plant Biology, University of Geneva) (Bartels et al. 2009). The T-DNA insertional mutant for the transporter of proline AtProT2 (At3g55740) (atprot2-3, SALK_067508) was obtained from Nottingham Arabidopsis Stock Centre (Alonso et al. 2003). The following lines in the Col-0 background also were used in this study: agb1-2 (Ullah et al. 2003), fls2 (Zipfel et al. 2004), cpr5 (Bowling et al. 1997), NahG (Delaney et al. 1994), irxl-2 (Scheible et al. 2001) and irx1-6 (Hernandez-Blanco et al. 2007), cerk1-2 (Miya et al. 2007), sid2-1 (Nawrath and Métraux 1999), rbohD (Torres et al. 2002), and 35S::RBOHD (Kadota et al. 2014). Double mutants were generated by standard genetic crosses followed by identification of homozygous lines by PCR. Primers used for genotyping are depicted in Supplementary Table S1.

\section{Genetic mapping of $S G B 10$.}

For the suppressor screening of $a g b l-2$ and EMSmutagenized population was used (Escudero et al. 2017). A sgb10 (Col-0) $\times$ La-0 F2 population of 1,980 individuals was generated to map the $S G B 10$ gene. These F2 plants were selected based on their lesion phenotype. The sgblo/mkpl mutation was mapped to chromosome 3 between markers cer451778 (bacterial artificial chromosome [BAC] F28P10, one recombinant) and cer479349 (BAC T5P19, two recombinants), using the primers described in Supplementary Table S2. Genomic DNA from sgblo plants was fully sequenced to position the sgb10/mkpl mutation (Illumina Technology, BGI, Hong Kong) and a single nucleotide transition was found in the MKP1 gene (At3g55270). sgb10 and sgb10 agbl-2 lines were backcrossed five times before performing all the assays.

\section{Pathogenicity assays.}

Arabidopsis resistance analyses against Plectosphaerella cucumerina BMM were performed by spraying with a $4 \times 10^{6}$ fungal spores/ml suspension 18-day-old seedlings grown under short-day conditions. Subsequently, plants were kept under high relative humidity until tissue collection or visual scoring. Relative quantification of fungal DNA was performed by qPCR on genomic DNA extracted from infected plants, using primers specific for $\beta$-tubulin from the fungus and ubiquitin from Arabidopsis, as described by Escudero et al. (2017). agbl-2 (Ullah et al. 2003) and irxl-6 (Hernandez-Blanco et al. 2007) plants were used as negative and positive controls, respectively. A minimum of 20 plants per genotype were used in each experiment. Inoculations with Hyaloperonospora arabidopsidis Noco 2 isolate $\left(4 \times 10^{4}\right.$ spores $\left./ \mathrm{ml}\right)$ were performed on 12-dayold seedlings. Inoculated plants were kept under a sealed lid to achieve high relative humidity and progression of the infection was scored after 7 days, as previously described (Llorente et al. 2005). agbl-2 (Ullah et al. 2003) and La-0 plants were used as negative and positive controls, respectively. Pseudomonas syringae pv. tomato DC3000 (optical density at $600 \mathrm{~nm}$ of 0.2) was spray-inoculated onto 3 -week-old plants following 
standard procedures (Escudero et al. 2017). fls2 (Zipfel et al 2004) and cpr5 (Bowling et al. 1997) plants were used as negative and positive controls, respectively. These experiments were repeated at least twice with identical results.

\section{Trypan blue and diaminobenzidine (DAB) staining.}

Seedlings inoculated with $H$. arabidopsisdis isolate Noco2 were collected at 7 dpi and lactophenol trypan-blue staining was done as described (Llorente et al. 2008). The same procedure was done on leaves from adult plants. DAB staining on adult plants was performed as described by Escudero et al. (2017).

\section{Evaluation of PAMP-triggered immune responses.}

A luminol-based assay was used to monitor $\mathrm{H}_{2} \mathrm{O}_{2}$ production on leaf discs from 4-week-old plants after applying $100 \mathrm{nM}$ flg22, $100 \mathrm{nM}$ elf18, and $1 \mathrm{mg}$ of chitin per milliliter, as described previously (Torres et al. 2013). MAPK activation assays were carried out as described by Escudero et al. (2017). In these experiments 12-day-old seedlings were harvested at $0,2,5,10$, 20,30 , and $45 \mathrm{~min}$ after elicitation with $1 \mu \mathrm{M}$ flg 22 .

\section{Gene expression analysis.}

RNA extractions from 12-day-old seedlings (grown in vitro) and adult plants (grown in soil) and quantitative real-time reverse transcription PCR analyses were performed as reported (Jordá et al. 2016). Treatment with flagellin $(1 \mu \mathrm{M})$ was performed on 12-day-old seedlings, and tissues were collected for gene expression at time 0 and 30 min after flg22 treatment. UBC21 (At5g25760) expression was used to normalize the transcript level in each reaction. Oligonucleotides used for detection of gene expression are detailed in Supplementary Table S3.

\section{Global metabolomic profile.}

Tissues from 25-day-old Col-0 and mkpl-2 plants $(n=10)$ grown in short-day conditions were collected, were ground in liquid nitrogen, and were lyophilized. Four biological replicates for each genotype were further processed and analyzed by Metabolon Inc. (Raleigh, NC, U.S.A.) as described (Ren et al. 2012).

\section{Morphometric analyses and screen for agb1-2 hypocotyl and hook phenotypes.}

Morphometric analyses and measurement of the hypocotyls were performed as described previously by Jordá et al. (2016). One-way analysis of variance was used to determine differences between the different genotypes (Bonferroni post hoc test, $P<0.05$ )

\section{Isoxaben inhibition assays.}

Arabidopsis seeds were sterilized and plated onto $1 / 2 \mathrm{MS}$ plates with $4 \mathrm{nM}$ isoxaben or without (control plants). After 2 days in the dark at $4^{\circ} \mathrm{C}$, plates were moved to long-day conditions and were placed vertically. Ten days after germination, root lengths were measured and the percentage of inhibition was estimated relative to control plants. irx 1-2 plants were included as resistant control (Scheible et al. 2001).

\section{ACKNOWLEDGMENTS}

We gratefully thank R. Ulm (Department of Botany and Plant Biology, University of Geneva) for providing $m k p 1-1$ and $35 S:: M K P 1$ seeds.

\section{LITERATURE CITED}

Adachi, H., Nakano, T., Miyagawa, N., Ishihama, N., Yoshioka, M., Katou, Y., Yaeno, T., Shirasu, K., and Yoshioka, H. 2015. WRKY transcription factors phosphorylated by MAPK regulate a plant immune NADPH oxidase in Nicotiana benthamiana. Plant Cell 27:2645-2663.

Alonso, J. M., Stepanova, A. N., Leisse, T. J., Kim, C. J., Chen, H., Shinn, P., Stevenson, D. K., Zimmerman, J., Barajas, P., Cheuk, R., Gadrinab, C., Heller, C., Jeske, A., Koesema, E., Meyers, C. C., Parker, H., Prednis, L., Ansari, Y., Choy, N., Deen, H., Geralt, M., Hazari, N., Hom, E., Karnes, M., Mulholland, C., Ndubaku, R., Schmidt, I., Guzman, P. Aguilar-Henonin, L., Schmid, M., Weigel, D., Carter, D. E., Marchand, T., Risseeuw, E., Brogden, D., Zeko, A., Crosby, W. L., Berry, C. C., and Ecker, J. R. 2003. Genome-wide insertional mutagenesis of Arabidopsis thaliana. Science 301:653-657.

Anderson, J. C., Bartels, S., González Besteiro, M. A., Shahollari, B., Ulm R., and Peck, S. C. 2011. Arabidopsis MAP kinase phosphatase 1 (AtMKP1) negatively regulates MPK6-mediated PAMP responses and resistance against bacteria. Plant J. 67:258-268.

Anderson, J. C., Wan, Y., Kim, Y. M., Pasa-Tolic, L., Metz, T. O., and Peck, S. C. 2014. Decreased abundance of type III secretion system-inducing signals in Arabidopsis mkpl enhances resistance against Pseudomonas syringae. Proc. Natl. Acad. Sci. U.S.A. 111:6846-6851.

Aranda-Sicilia, M. N., Trusov, Y., Maruta, N., Chakravorty, D., Zhang, Y., and Botella, J. R. 2015. Heterotrimeric G proteins interact with defenserelated receptor-like kinases in Arabidopsis. J. Plant Physiol. 188:44-48.

Asai, T., Tena, G., Plotnikova, J., Willmann, M. R., Chiu, W.-L., GomezGomez, L., Boller, T., Ausubel, F. M., and Sheen, J. 2002. MAP kinase signalling cascade in Arabidopsis innate immunity. Nature 415:977-983.

Bartels, S., Anderson, J. C., González Besteiro, M. A., Carreri, A., Hirt, H., Buchala, A., Métraux, J. P., Peck, S. C., and Ulm, R. 2009. MAP KINASE PHOSPHATASE1 and PROTEIN TYROSINE PHOSPHATASE1 are repressors of salicylic acid synthesis and SNC1-mediated responses in Arabidopsis. Plant Cell 21:2884-2897.

Bartels, S., González Besteiro, M. A., Lang, D., and Ulm, R. 2010. Emerging functions for plant MAP kinase phosphatases. Trends Plant Sci. 15:322-329.

Berrocal-Lobo, M., Molina, A., and Solano, R. 2002. Constitutive expression of ETHYLENE-RESPONSE-FACTOR1 in Arabidopsis confers resistance to several necrotrophic fungi. Plant J. 29:23-32.

Bi, G., and Zhou, J. M. 2017. MAP kinase signaling pathways: A hub of plant-microbe interactions. Cell Host Microbe 21:270-273.

Böhm, H., Albert, I., Fan, L., Reinhard, A., and Nürnberger, T. 2014. Immune receptor complexes at the plant cell surface. Curr. Opin. Plant Biol. 20:47-54

Boudsocq, M., Willmann, M. R., McCormack, M., Lee, H., Shan, L., He, P. Bush, J., Cheng, S.-H., and Sheen, J. 2010. Differential innate immune signalling via $\mathrm{Ca}^{2+}$ sensor protein kinases. Nature 464:418-422.

Bowling, S. A., Clarke, J. D., Liu, Y., Klessig, D. F., and Dong, X. 1997. The cpr5 mutant of Arabidopsis expresses both NPR1-dependent and NPR1-independent resistance. Plant Cell 9:1573-1584.

Brenya, E., Trusov, Y., Dietzgen, R. G., and Botella, J. R. 2016. Heterotrimeric G-proteins facilitate resistance to plant pathogenic viruses in Arabidopsis thaliana (L.) Heynh. Plant Signal. Behav. 11:e1212798.

Campos, L., Granell, P., Tárraga, S., López-Gresa, P., Conejero, V., Bellés, J. M., Rodrigo, I., and Lisón, P. 2014. Salicylic acid and gentisic acid induce RNA silencing-related genes and plant resistance to RNA pathogens. Plant Physiol. Biochem. 77:35-43.

Cao, Y., Liang, Y., Tanaka, K., Nguyen, C. T., Jedrzejczak, R. P., Joachimiak, A., and Stacey, G. 2014. The kinase LYK5 is a major chitin receptor in Arabidopsis and forms a chitin-induced complex with related kinase CERK1. eLife 3:3.

Chakravorty, D., Gookin, T. E., Milner, M. J., Yu, Y., and Assmann, S. M. 2015. Extra-large $G$ proteins expand the repertoire of subunits in Arabidopsis heterotrimeric $G$ protein signaling. Plant Physiol. 169: 512-529.

Chen, Y. C., Holmes, E. C., Rajniak, J., Kim, J. G., Tang, S., Fischer, C. R., Mudgett, M. B., and Sattely, E. S. 2018. $N$-hydroxy-pipecolic acid is a mobile metabolite that induces systemic disease resistance in Arabidopsis. Proc. Natl. Acad. Sci. U.S.A. 115:E4920-E4929.

Cheng, Z., Li, J. F., Niu, Y., Zhang, X. C., Woody, O. Z., Xiong, Y., Djonović, S., Millet, Y., Bush, J., McConkey, B. J., Sheen, J., and Ausubel, F. M. 2015. Pathogen-secreted proteases activate a novel plant immune pathway. Nature 521:213-216.

Couto, D., and Zipfel, C. 2016. Regulation of pattern recognition receptor signalling in plants. Nat. Rev. Immunol. 16:537-552.

Delaney, T. P., Uknes, S., Vernooij, B., Friedrich, L., Weymann, K., Negrotto, D., Gaffney, T., Gut-Rella, M., Kessmann, H., Ward, E., and Ryals, J. 1994. A central role of salicylic acid in plant disease resistance. Science 266:1247-1250.

Delgado-Cerezo, M., Sánchez-Rodríguez, C., Escudero, V., Miedes, E., Fernández, P. V., Jordá, L., Hernández-Blanco, C., Sánchez-Vallet, A., 
Bednarek, P., Schulze-Lefert, P., Somerville, S., Estevez, J. M., Persson, S., and Molina, A. 2012. Arabidopsis heterotrimeric G-protein regulates cell wall defense and resistance to necrotrophic fungi. Mol. Plant 5: 98-114.

Dubiella, U., Seybold, H., Durian, G., Komander, E., Lassig, R., Witte, C. P., Schulze, W. X., and Romeis, T. 2013. Calcium-dependent protein kinase/NADPH oxidase activation circuit is required for rapid defense signal propagation. Proc. Natl. Acad. Sci. U.S.A. 110:8744-8749.

Escudero, V., Jordá, L., Sopeña-Torres, S., Mélida, H., Miedes, E., MuñozBarrios, A., Swami, S., Alexander, D., McKee, L. S., Sánchez-Vallet, A., Bulone, V., Jones, A. M., and Molina, A. 2017. Alteration of cell wall xylan acetylation triggers defense responses that counterbalance the immune deficiencies of plants impaired in the $\beta$-subunit of the heterotrimeric G-protein. Plant J. 92:386-399.

Friedman, E. J., Wang, H. X., Jiang, K., Perovic, I., Deshpande, A., Pochapsky, T. C., Temple, B. R., Hicks, S. N., Harden, T. K., and Jones, A. M. 2011. Acireductone dioxygenase 1 (ARD1) is an effector of the heterotrimeric G protein beta subunit in Arabidopsis. J. Biol. Chem. 286: 30107-30118.

Galletti, R., Ferrari, S., and De Lorenzo, G. 2011. Arabidopsis MPK3 and MPK6 play different roles in basal and oligogalacturonide- or flagellininduced resistance against Botrytis cinerea. Plant Physiol. 157:804-814.

González Besteiro, M. A., and Ulm, R. 2013. ATR and MKP1 play distinct roles in response to UV-B stress in Arabidopsis. Plant J. 73:1034-1043.

Hartmann, M., Zeier, T., Bernsdorff, F., Reichel-Deland, V., Kim, D., Hohmann, M., Scholten, N., Schuck, S., Brautigam, A., Holzel, T., Ganter, C., and Zeier, J. 2018. Flavin monooxygenase-generated Nhydroxypipecolic acid is a critical element of plant systemic immunity. Cell 173:456-469.

Hernández-Blanco, C., Feng, D. X., Hu, J., Sánchez-Vallet, A., Deslandes, L., Llorente, F., Berrocal-Lobo, M., Keller, H., Barlet, X., SánchezRodríguez, C., Anderson, L. K., Somerville, S., Marco, Y., and Molina, A. 2007. Impairment of cellulose synthases required for Arabidopsis secondary cell wall formation enhances disease resistance. Plant Cell 19: 890-903.

Ishida, T., Tabata, R., Yamada, M., Aida, M., Mitsumasu, K., Fujiwara, M., Yamaguchi, K., Shigenobu, S., Higuchi, M., Tsuji, H., Shimamoto, K., Hasebe, M., Fukuda, H., and Sawa, S. 2014. Heterotrimeric G proteins control stem cell proliferation through CLAVATA signaling in Arabidopsis. EMBO Rep. 15:1202-1209.

Ishikawa, A. 2009. The Arabidopsis G-protein $\beta$-subunit is required for defense response against Agrobacterium tumefaciens. Biosci. Biotechnol. Biochem. 73:47-52.

Jiang, L., Anderson, J. C., Gonzalez Besteiro, M. A., and Peck, S. C. 2017a. Phosphorylation of Arabidopsis MAP kinase phosphatase 1 (MKP1) is required for PAMP responses and resistance against bacteria. Plant Physiol. 175:1839-1852.

Jiang, L., Wan, Y., Anderson, J. C., Hou, J., Islam, S. M., Cheng, J., and Peck, S. C. 2017b. Genetic dissection of Arabidopsis MAP kinase phosphatase 1-dependent PAMP-induced transcriptional responses. J. Exp. Bot. 68:5207-5220.

Jordá, L., Sopeña-Torres, S., Escudero, V., Nuñez-Corcuera, B., DelgadoCerezo, M., Torii, K. U., and Molina, A. 2016. ERECTA and bak1 receptor like kinases interact to regulate immune responses in Arabidopsis. Front. Plant Sci. 7:897.

Kadota, Y., Shirasu, K., and Zipfel, C. 2015. Regulation of the NADPH oxidase RBOHD during plant immunity. Plant Cell Physiol. 56: 1472-1480.

Kadota, Y., Sklenar, J., Derbyshire, P., Stransfeld, L., Asai, S., Ntoukakis, V., Jones, J. D., Shirasu, K., Menke, F., Jones, A., and Zipfel, C. 2014 Direct regulation of the NADPH oxidase RBOHD by the PRRassociated kinase BIK1 during plant immunity. Mol. Cell 54:43-55.

Katou, S., Kuroda, K., Seo, S., Yanagawa, Y., Tsuge, T., Yamazaki, M., Miyao, A., Hirochika, H., and Ohashi, Y. 2007. A calmodulin-binding mitogen-activated protein kinase phosphatase is induced by wounding and regulates the activities of stress-related mitogen-activated protein kinases in rice. Plant Cell Physiol. 48:332-344.

Klopffleisch, K., Phan, N., Augustin, K., Bayne, R. S., Booker, K. S., Botella, J. R., Carpita, N. C., Carr, T., Chen, J. G., Cooke, T. R., FrickCheng, A., Friedman, E. J., Fulk, B., Hahn, M. G., Jiang, K., Jorda, L. Kruppe, L., Liu, C., Lorek, J., McCann, M. C., Molina, A., Moriyama, E. N., Mukhtar, M. S., Mudgil, Y., Pattathil, S., Schwarz, J., Seta, S., Tan, M., Temp, U., Trusov, Y., Urano, D., Welter, B., Yang, J., Panstruga, R., Uhrig, J. F., and Jones, A. M. 2011. Arabidopsis G-protein interactome reveals connections to cell wall carbohydrates and morphogenesis. Mol. Syst. Biol. 7:532.

Kobayashi, M., Ohura, I., Kawakita, K., Yokota, N., Fujiwara, M., Shimamoto, K., Doke, N., and Yoshioka, H. 2007. Calcium-dependent protein kinases regulate the production of reactive oxygen species by potato NADPH oxidase. Plant Cell 19:1065-1080.

Lehmann, S., Gumy, C., Blatter, E., Boeffel, S., Fricke, W., and Rentsch, D 2011. In planta function of compatible solute transporters of the AtProT family. J. Exp. Bot. 62:787-796.

Li, L., Li, M., Yu, L., Zhou, Z., Liang, X., Liu, Z., Cai, G., Gao, L., Zhang, X., Wang, Y., Chen, S., and Zhou, J.-M. 2014. The FLS2-associated kinase BIK1 directly phosphorylates the NADPH oxidase RbohD to control plant immunity. Cell Host Microbe 15:329-338.

Liang, X., Ding, P., Lian, K., Wang, J., Ma, M., Li, L., Li, L., Li, M., Zhang, X., Chen, S., Zhang, Y., and Zhou, J. M. 2016. Arabidopsis heterotrimeric $\mathrm{G}$ proteins regulate immunity by directly coupling to the FLS2 receptor. eLife 5:e13568.

Liu, J., Ding, P., Sun, T., Nitta, Y., Dong, O., Huang, X., Yang, W., Li, X., Botella, J. R., and Zhang, Y. 2013. Heterotrimeric G proteins serve as a converging point in plant defense signaling activated by multiple receptor-like kinases. Plant Physiol. 161:2146-2158.

Liu, J. Z., and Whitham, S. A. 2013. Overexpression of a soybean nuclear localized type-III DnaJ domain-containing HSP40 reveals its roles in cell death and disease resistance. Plant J. 74:110-121.

Llorente, F., Alonso-Blanco, C., Sánchez-Rodriguez, C., Jorda, L., and Molina, A. 2005. ERECTA receptor-like kinase and heterotrimeric G protein from Arabidopsis are required for resistance to the necrotrophic fungus Plectosphaerella cucumerina. Plant J. 43:165-180.

Llorente, F., Muskett, P., Sánchez-Vallet, A., López, G., Ramos, B., Sánchez-Rodríguez, C., Jordá, L., Parker, J., and Molina, A. 2008. Repression of the auxin response pathway increases Arabidopsis susceptibility to necrotrophic fungi. Mol. Plant 1:496-509.

Lorek, J., Griebel, T., Jones, A. M., Kuhn, H., and Panstruga, R. 2013. The role of Arabidopsis heterotrimeric G-protein subunits in MLO2 function and MAMP-triggered immunity. Mol. Plant-Microbe Interact 26: 991-1003.

Marino, D., Dunand, C., Puppo, A., and Pauly, N. 2012. A burst of plant NADPH oxidases. Trends Plant Sci. 17:9-15.

Maruta, N., Trusov, Y., Brenya, E., Parekh, U., and Botella, J. R. 2015. Membrane-localized extra-large $G$ proteins and $G \beta \gamma$ of the heterotrimeric $\mathrm{G}$ proteins form functional complexes engaged in plant immunity in Arabidopsis. Plant Physiol. 167:1004-1016.

Mersmann, S., Bourdais, G., Rietz, S., and Robatzek, S. 2010. Ethylene signaling regulates accumulation of the FLS2 receptor and is required for the oxidative burst contributing to plant immunity. Plant Physiol. 154: 391-400.

Miya, A., Albert, P., Shinya, T., Desaki, Y., Ichimura, K., Shirasu, K., Narusaka, Y., Kawakami, N., Kaku, H., and Shibuya, N. 2007. CERK1, a LysM receptor kinase, is essential for chitin elicitor signaling in Arabidopsis. Proc. Natl. Acad. Sci. U.S.A. 104:19613-19618.

Morales, J., Kadota, Y., Zipfel, C., Molina, A., and Torres, M.-A. 2016. The Arabidopsis NADPH oxidases $R b o h D$ and $R b o h F$ display differential expression patterns and contributions during plant immunity. J. Exp. Bot. 67:1663-1676.

Nawrath, C., and Métraux, J. P. 1999. Salicylic acid induction-deficient mutants of Arabidopsis express PR-2 and PR-5 and accumulate high levels of camalexin after pathogen inoculation. Plant Cell 11:1393-1404.

Park, A. R., Cho, S. K., Yun, U. J., Jin, M. Y., Lee, S. H., Sachetto-Martins, G., and Park, O. K. 2001. Interaction of the Arabidopsis receptor protein kinase Wak1 with a glycine-rich protein, AtGRP-3. J. Biol. Chem. 276: 26688-26693.

Parker, J. E., Coleman, M. J., Szabò, V., Frost, L. N., Schmidt, R., van der Biezen, E. A., Moores, T., Dean, C., Daniels, M. J., and Jones, J. D. 1997. The Arabidopsis downy mildew resistance gene RPP5 shares similarity to the toll and interleukin-1 receptors with $\mathrm{N}$ and L6. Plant Cell 9: 879-894.

Pogány, M., von Rad, U., Grün, S., Dongó, A., Pintye, A., Simoneau, P. Bahnweg, G., Kiss, L., Barna, B., and Durner, J. 2009. Dual roles of reactive oxygen species and NADPH oxidase RBOHD in an Arabidopsis-Alternaria pathosystem. Plant Physiol. 151:1459-1475.

Ren, D., Yang, H., and Zhang, S. 2002. Cell death mediated by MAPK is associated with hydrogen peroxide production in Arabidopsis. J. Biol. Chem. 277:559-565.

Ren, M., Venglat, P., Qiu, S., Feng, L., Cao, Y., Wang, E., Xiang, D., Wang, J., Alexander, D., Chalivendra, S., Logan, D., Mattoo, A., Selvaraj, G., and Datla, R. 2012. Target of rapamycin signaling regulates metabolism, growth, and life span in Arabidopsis. Plant Cell 24:4850-4874.

Samuel, M. A., Hall, H., Krzymowska, M., Drzewiecka, K., Hennig, J., and Ellis, B. E. 2005. SIPK signaling controls multiple components of harpin-induced cell death in tobacco. Plant J. 42:406-416.

Sánchez-Vallet, A., López, G., Ramos, B., Delgado-Cerezo, M., Riviere, M. P., Llorente, F., Fernández, P. V., Miedes, E., Estevez, J. M., Grant, 
M., and Molina, A. 2012. Disruption of abscisic acid signaling constitutively activates Arabidopsis resistance to the necrotrophic fungus Plectosphaerella cucumerina. Plant Physiol. 160:2109-2124.

Sanchez-Vallet, A., Ramos, B., Bednarek, P., López, G., PiślewskaBednarek, M., Schulze-Lefert, P., and Molina, A. 2010. Tryptophanderived secondary metabolites in Arabidopsis thaliana confer non-host resistance to necrotrophic Plectosphaerella cucumerina fungi. Plant J. 63:115-127.

Scheible, W. R., Eshed, R., Richmond, T., Delmer, D., and Somerville, C. 2001. Modifications of cellulose synthase confer resistance to isoxaben and thiazolidinone herbicides in Arabidopsis Ixr1 mutants. Proc. Natl. Acad. Sci. U.S.A. 98:10079-10084.

Seyfferth, C., and Tsuda, K. 2014. Salicylic acid signal transduction: The initiation of biosynthesis, perception and transcriptional reprogramming. Front. Plant Sci. 5:697.

Sopeña-Torres, S., Jordá, L., Sánchez-Rodríguez, C., Miedes, E., Escudero, V., Swami, S., López, G., Piślewska-Bednarek, M., Lassowskat, I., Lee, J., Gu, Y., Haigis, S., Alexander, D., Pattathil, S., Muñoz-Barrios, A., Bednarek, P., Somerville, S., Schulze-Lefert, P., Hahn, M. G., Scheel, D., and Molina, A. 2018. YODA MAP3K kinase regulates plant immune responses conferring broad-spectrum disease resistance. New Phytol. 218:661-680.

Sun, T., Nitta, Y., Zhang, Q., Wu, D., Tian, H., Lee, J. S., and Zhang, Y. 2018. Antagonistic interactions between two MAP kinase cascades in plant development and immune signaling. EMBO Rep. 19:19.

Takahashi, F., Yoshida, R., Ichimura, K., Mizoguchi, T., Seo, S., Yonezawa, M., Maruyama, K., Yamaguchi-Shinozaki, K., and Shinozaki, K. 2007. The mitogen-activated protein kinase cascade MKK3-MPK6 is an important part of the jasmonate signal transduction pathway in Arabidopsis. Plant Cell 19:805-818.

Tamnanloo, F., Damen, H., Jangra, R., and Lee, J. S. 2018. MAP KINASE PHOSPHATASE1 controls cell fate transition during stomatal development. Plant Physiol. 178:247-257.

Temple, B. R., and Jones, A. M. 2007. The plant heterotrimeric G-protein complex. Annu. Rev. Plant Biol. 58:249-266.

Torres, M. A., and Dangl, J. L. 2005. Functions of the respiratory burst oxidase in biotic interactions, abiotic stress and development. Curr. Opin. Plant Biol. 8:397-403.

Torres, M. A., Dangl, J. L., and Jones, J. D. 2002. Arabidopsis gp91 ${ }^{\text {phox }}$ homologues AtrbohD and AtrbohF are required for accumulation of reactive oxygen intermediates in the plant defense response. Proc. Natl. Acad. Sci. U.S.A. 99:517-522.

Torres, M. A., Jones, J. D., and Dangl, J. L. 2005. Pathogen-induced, NADPH oxidase-derived reactive oxygen intermediates suppress spread of cell death in Arabidopsis thaliana. Nat. Genet. 37:1130-1134.

Torres, M. A., Morales, J., Sánchez-Rodríguez, C., Molina, A., and Dangl, J. L. 2013. Functional interplay between Arabidopsis NADPH oxidases and heterotrimeric G protein. Mol. Plant-Microbe Interact 26:686-694.

Trusov, Y., Rookes, J. E., Chakravorty, D., Armour, D., Schenk, P. M., and Botella, J. R. 2006. Heterotrimeric G proteins facilitate Arabidopsis resistance to necrotrophic pathogens and are involved in jasmonate signaling. Plant Physiol. 140:210-220.

Tunc-Ozdemir, M., and Jones, A. M. 2017. Ligand-induced dynamics of heterotrimeric $\mathrm{G}$ protein-coupled receptor-like kinase complexes. PLoS One 12:e0171854.

Tunc-Ozdemir, M., Urano, D., Jaiswal, D. K., Clouse, S. D., and Jones, A. M. 2016. Direct modulation of heterotrimeric $G$ protein-coupled signaling by a receptor kinase complex. J. Biol. Chem. 291 : 13918-13925.

Ullah, H., Chen, J. G., Temple, B., Boyes, D. C., Alonso, J. M., Davis, K. R., Ecker, J. R., and Jones, A. M. 2003. The $\beta$-subunit of the Arabidopsis $\mathrm{G}$ protein negatively regulates auxin-induced cell division and affects multiple developmental processes. Plant Cell 15:393-409.

Ullah, H., Chen, J. G., Young, J. C., Im, K. H., Sussman, M. R., and Jones, A. M. 2001. Modulation of cell proliferation by heterotrimeric $\mathrm{G}$ protein in Arabidopsis. Science 292:2066-2069.

Ulm, R., Ichimura, K., Mizoguchi, T., Peck, S. C., Zhu, T., Wang, X., Shinozaki, K., and Paszkowski, J. 2002. Distinct regulation of salinity and genotoxic stress responses by Arabidopsis MAP kinase phosphatase 1. EMBO J. 21:6483-6493.

Ulm, R., Revenkova, E., di Sansebastiano, G. P., Bechtold, N., and Paszkowski, J. 2001. Mitogen-activated protein kinase phosphatase is required for genotoxic stress relief in Arabidopsis. Genes Dev. 15:699-709.

Urano, D., and Jones, A. M. 2014. Heterotrimeric G protein-coupled signaling in plants. Annu. Rev. Plant Biol. 65:365-384.

Urano, D., Maruta, N., Trusov, Y., Stoian, R., Wu, Q., Liang, Y., Jaiswal, D. K., Thung, L., Jackson, D., Botella, J. R., and Jones, A. M. 2016 b. Saltational evolution of the heterotrimeric $G$ protein signaling mechanisms in the plant kingdom. Sci. Signal. 9:ra93.

Urano, D., Miura, K., Wu, Q., Iwasaki, Y., Jackson, D., and Jones, A. M. 2016a. Plant morphology of heterotrimeric G protein mutants. Plant Cell Physiol. 57:437-445.

Urbanowicz, B. R., Peña, M. J., Moniz, H. A., Moremen, K. W., and York, W. S. 2014. Two Arabidopsis proteins synthesize acetylated xylan in vitro. Plant J. 80:197-206.

Wang, C., Liu, R., Lim, G.H., de Lorenzo, L., Yu, K., Zhang, K., Hunt, A.G., Kachroo, A., and Kachroo, P. 2018a. Pipecolic acid confers systemic immunity by regulating free radicals. Sci. Adv. 4:eaar4509.

Wang, H. X., Weerasinghe, R. R., Perdue, T. D., Cakmakci, N. G., Taylor, J. P., Marzluff, W. F., and Jones, A. M. 2006. A Golgi-localized hexose transporter is involved in heterotrimeric G protein-mediated early development in Arabidopsis. Mol. Biol. Cell 17:4257-4269.

Wang, J., Grubb, L. E., Wang, J., Liang, X., Li, L., Gao, C., Ma, M., Feng, F., Li, M., Li, L., Zhang, X., Yu, F., Xie, Q., Chen, S., Zipfel, C., Monaghan, J., and Zhou, J. M. 2018b. A regulatory module controlling homeostasis of a plant immune kinase. Mol. Cell 69:P493-504.E6.

Wildermuth, M. C., Dewdney, J., Wu, G., and Ausubel, F. M. 2001. Isochorismate synthase is required to synthesize salicylic acid for plant defence. Nature 414:562-565.

$\mathrm{Xu}$, J., and Zhang, S. 2015. Mitogen-activated protein kinase cascades in signaling plant growth and development. Trends Plant Sci. 20:56-64.

Yuan, G. L., Li, H. J., and Yang, W. C. 2017. The integration of G $\beta$ and MAPK signaling cascade in zygote development. Sci. Rep. 7:8732.

Zhang, J., Shao, F., Li, Y., Cui, H., Chen, L., Li, H., Zou, Y., Long, C., Lan, L., Chai, J., Chen, S., Tang, X., and Zhou, J. M. 2007. A Pseudomonas syringae effector inactivates MAPKs to suppress PAMP-induced immunity in plants. Cell Host Microbe 1:175-185.

Zhu, H., Li, G. J., Ding, L., Cui, X., Berg, H., Assmann, S. M., and Xia, Y. 2009. Arabidopsis extra large G-protein 2 (XLG2) interacts with the G $\beta$ subunit of heterotrimeric $\mathrm{G}$ protein and functions in disease resistance. Mol. Plant 2:513-525.

Zipfel, C., Robatzek, S., Navarro, L., Oakeley, E. J., Jones, J. D., Felix, G., and Boller, T. 2004. Bacterial disease resistance in Arabidopsis through flagellin perception. Nature 428:764-767. 